\title{
Novel transformation-based response prediction of shear building using interval neural network
}

\author{
S Chakraverty* and Deepti Moy Sahoo \\ Department of Mathematics, National Institute of Technology Rourkela, Rourkela 769 008, Odisha, India. \\ ${ }^{*}$ Corresponding author. e-mail: sne_chak@yahoo.com
}

Present paper uses powerful technique of interval neural network (INN) to simulate and estimate structural response of multi-storey shear buildings subject to earthquake motion. The INN is first trained for a real earthquake data, viz., the ground acceleration as input and the numerically generated responses of different floors of multi-storey buildings as output. Till date, no model exists to handle positive and negative data in the INN. As such here, the bipolar data in $[-1,1]$ are converted first to unipolar form, i.e., to $[0,1]$ by means of a novel transformation for the first time to handle the above training patterns in normalized form. Once the training is done, again the unipolar data are converted back to its bipolar form by using the inverse transformation. The trained INN architecture is then used to simulate and test the structural response of different floors for various intensity earthquake data and it is found that the predicted responses given by INN model are good for practical purposes.

\section{Introduction}

Earthquake is one of the natural calamities which cause loss to human beings. Earthquake ground motion at a particular building site is very complicated. This earthquake ground motion, when it is strong enough sets the building in motion, starting with the foundation and transfers the motion throughout the rest of the building in a very complex way. Dynamic response of a structure subject to strong earthquake ground motion may be investigated by different methods. One of these methods consists of constructing a good theoretical model of a structure and calculating the dynamic response for an assumed known motion of the foundation. The other method used is to create a trained black box containing the characteristics of the structure and of the earthquake motion that can predict the dynamic response for any other earthquake for a particular structure.
Several studies have already been done to identify structural parameters with the help of seismic response data. Wang and Cui (2008) proposed a two-step method for simultaneous identification of structural parameters with unknown ground motion. A procedure for nonlinear system identification using prediction error identification method with state-space description is presented in Furukawa et al. (2005). A modified random decrement method together with the Ibrahim time-domain technique has been used by Lin et al. (2005) to evaluate the modal frequencies, damping ratios and mode shapes of an asymmetric building. Xu et al. (2014) proposed a new computational method based on linear and nonlinear regression analysis techniques, for identification of the linear and nonlinear physical parameters of base-isolated multi-storey buildings using earthquake records.

The artificial neural network (ANN) has gradually been established as a powerful tool in various fields

Keywords. Interval neural network; shear buildings; response; earthquake; structure 
because of its excellent learning capacity and high tolerance to partially inaccurate data. ANN has recently been applied to assess damage in structures. A back-propagation neural network $(\mathrm{BPN})$ to elucidate damage states in a three-storey frame by numerical simulation has been studied by $\mathrm{Wu}$ et al. (1992). Conte and Durrani (1994) gave a neural network-based approach to model the seismic response of multi-storey frame buildings. Pandey and Barai (1995) detected damage in a bridge truss by applying ANN to numerically simulated data. A counter-propagation neural network (NN) to locate damage in beams and frames has been studied by Zhao et al. (1998). Masri et al. (2000) used BPN for detecting damage, based on nonlinear system identification. A novel procedure for identifying dynamic characteristics of a building from seismic response data using NN model has been given by Huang et al. (2003). Mathur et al. (2004) used feed forward, multilayer, supervised neural network with error back propagation algorithm to predict responses of typical rural house subject to earthquake motions. Chakraverty et al. (2006, 2009) applied neural network model for response prediction of structural system subject to earthquake motions. An application of neural network model for earthquake prediction in east China has been presented by Xie et al. (2011). Some of the other related publication may be given as Reyes et al. (2012); Alvarez et al. (2013); Niksarlioglu and Kulahci (2013); and Sriram et al. (2014). It may be seen from the above that ANNs provide a fundamentally different approach to system identification and dynamic problems.

It may be seen from above literature review that ANN has been used for response prediction and damage detection. Traditional ANN has been used by previous authors because the data used by them are in exact or crisp form. But, it is not always possible to get the data in crisp or exact form because, in actual practice, those are obtained from experiments. As such, it is certain to have errors in the data. These may be due to human or equipment errors and then obtained data will be in uncertain form, which one may take as interval. In this regard, few authors have used nonprobabilistic method to solve different types of problems. If the available data are uncertain or nonprobabilistic in nature, then corresponding mathematical model/formulation needs to be developed. Here, interval neural network (INN) has been developed to handle uncertain or interval data. Few research works have been done using INN in other fields. Garczarczyk (2000) studied a four-layer feed forward network considering interval weights and interval biases. An application of interval valued neural networks to a regression problem has been presented by Chetwynd et al. (2006). Their work was concerned with exploiting uncertainty in order to develop a robust regression algorithm for a presliding friction process based on a nonlinear AutoRegressive with eXogeneous inputs neural network. Wang et al. (2010) used interval analysis technique for structural damage identification. Influences of uncertainties in the measurements and modelling errors on the identification were also investigated in this paper. Zhang et al. (2012) gave a numerically efficient approach to treat modelling errors with the help of intervals which results in bounding of the identified parameters. An interval GA (genetic algorithm) for evolving neural networks with interval weights and biases was developed by Okada et al. (2012), where they have proposed an extension of genetic algorithm for neuro-evolution of intervalvalued neural networks. Interval-based weight initialization method for a sigmoidal feedforward ANN has been given by Sodhi and Chandra (2013). Sahoo et al. (2014) proposed identification methodologies for multi-storey shear buildings using interval artificial neural network (IANN), which can estimate the structural parameters. Chakraverty and Sahoo (2014) used INN model to solve system identification problem of a multi-storey shear buildings using interval response data. $\mathrm{Lu}$ et al. (2015) presented an interval pattern matcher that can identify patterns with interval elements using neural networks.

It is worth mentioning that the earthquake acceleration data are actually both positive and negative. The INN cannot handle the data with negative sign due to the complexity in interval computation. Hence, after normalization of the input and output data, a transformation has been used here, which converts all the bipolar data to unipolar form. Accordingly, the data has been converted from the range $[-1,1]$ to $[0,1]$. After the data are converted within the range $[0,1]$, the INN algorithm is used and once the training is done again, the data are transferred back to its bipolar form by using the inverse transformation. Training and testing of the proposed model has been done following the above procedure. In this paper, the Chamoli and Uttarkashi earthquake recorded at Barkot, Uttarakhand, India in NE direction have been considered in interval form to get the storey responses in interval form. The Chamoli and Uttarkashi earthquakes occurred on 29th March 1999 and 20th October, 1991, respectively. The magnitude of Chamoli earthquake is $6.8 \mathrm{Mw}$ and its depth is about $21 \mathrm{~km}$, whereas the magnitude of Uttarkashi earthquake is $6.8 \mathrm{Mw}$ and its depth is $10 \mathrm{~km}$. The ground acceleration of Chamoli earthquake and the corresponding structural responses are trained using INN (all in interval form). After training, the converged weights are stored. In order to show the power of these converged (trained) 
networks, different intensities of Uttarkashi earthquakes are used as input and their storey responses are predicted in interval form. Similarly, various other simulations related to the use of these trained networks are discussed.

\section{Interval arithmetic}

Let us assume $A$ and $B$ as numbers expressed as intervals. For all $\underline{a}, \bar{a}, \underline{b}, \bar{b} \in R$ where $A=[\underline{a}, \bar{a}]$ and $B=[\underline{b}, \bar{b}]$, the main operations of intervals may be written as (Lee 2009):

(1) Addition

$$
[\underline{a}, \bar{a}](+)[\underline{b}, \bar{b}]=[\underline{a}+\underline{b}, \bar{a}+\bar{b}]
$$

(2) Subtraction

$$
[\underline{a}, \bar{a}](-)[\underline{b}, \bar{b}]=[\underline{a}-\bar{b}, \bar{a}-\underline{b}]
$$

(3) Multiplication

$$
\begin{aligned}
{[\underline{a}, \bar{a}](\times)[\underline{b}, \bar{b}]=} & {[\min (\underline{a} \times \underline{b}, \underline{a} \times \bar{b}, \bar{a} \times \underline{b}, \bar{a} \times \bar{b}),} \\
& \max (\underline{a} \times \underline{b}, \underline{a} \times \bar{b}, \bar{a} \times \underline{b}, \bar{a} \times \bar{b})]
\end{aligned}
$$

(4) Division

$$
\begin{aligned}
{[\underline{a}, \bar{a}](\div)[\underline{b}, \bar{b}]=} & {[\min (\underline{a} \div \underline{b}, \underline{a} \div \bar{b}, \bar{a} \div \underline{b}, \bar{a} \div \bar{b}),} \\
& \max (\underline{a} \div \underline{b}, \underline{a} \div \bar{b}, \bar{a} \div \underline{b}, \bar{a} \div \bar{b})]
\end{aligned}
$$

excluding the case $\underline{b}=0$ or $\bar{b}=0$.

\section{Architecture of multi-layer INN}

A neural network is said to be an interval neural network if at least one of its input, output and weights are in interval form. Here, architecture of feedforward neural network with interval inputs, weights, biases and outputs has been considered. In INNs, neurons are connected similar to the connection in traditional neural networks. As such, a multilayer INN is shown in figure 1 . Here $R$ inputoutput training pairs $\left\{\tilde{Z}_{1}, \tilde{d}_{1} ; \tilde{Z}_{2}, \tilde{d}_{2} ; \ldots ; \tilde{Z}_{R}, \tilde{d}_{R}\right\}$ are considered in interval form, where the inputs are $\tilde{Z}_{i}(I \times 1)$ and desired values for given inputs are $\tilde{d}_{i}(M \times 1)$. $\tilde{Z}_{i}, \tilde{P}_{j}$ and $\tilde{O}_{k}$ are the input, hidden and output layers, respectively. $\tilde{v}_{j i}$ are the weights between input and hidden layers and $\tilde{w}_{m j}$ are the weights between hidden and output layers. The inputs $\tilde{Z}_{i}=\tilde{\ddot{a}}_{i}=\left[\underline{\ddot{a}}_{i}, \overline{\ddot{a}}_{i}\right]$ are the ground acceleration and the outputs $\tilde{O}_{m}=\tilde{x}_{m}=\left[\underline{x}_{m}, \bar{x}_{m}\right]$ are responses of the structure, both in interval form.

\subsection{Learning algorithm of INN using bipolar activation function}

It may be noted here that the inputs are the ground acceleration, so the data are with both positive and negative signs.

The total input to the $j$ th hidden unit in the second layer is

$$
\begin{aligned}
\tilde{P}_{j} & =\left[\underline{P}_{j}, \bar{P}_{j}\right]=\sum_{i=1}^{I} \tilde{v}_{j i} \tilde{Z}_{i}+\tilde{\theta}_{j}, \\
j & =1,2, \ldots, J \text { and } i=1,2, \ldots, I .
\end{aligned}
$$

Here, $\tilde{\theta}_{j}$ is the interval bias weight of the hidden layer.

The output of the hidden unit is

$$
\tilde{U}_{j}=\left\lfloor\underline{U}_{j}, \bar{U}_{j}\right\rfloor=\left\lfloor f\left(\underline{P}_{j}\right), f\left(\bar{P}_{j}\right)\right\rfloor,
$$

where $\tilde{f}$ is the bipolar activation function defined by

$$
\tilde{f}\left(\tilde{P}_{j}\right)=\frac{1-\exp \left(-\gamma \tilde{P}_{j}\right)}{1+\exp \left(-\gamma \tilde{P}_{j}\right)}
$$

in interval form.

The total input from hidden to the output unit is

$$
\begin{gathered}
\tilde{Y}_{m}=\left[\underline{Y}_{m}, \bar{Y}_{m}\right]=\sum_{j=1}^{J} \tilde{w}_{m j} \tilde{U}_{j}+\tilde{\theta}_{m}, \\
m=1,2, \ldots, M \text { and } j=1,2, \ldots, J
\end{gathered}
$$

where $\tilde{\theta}_{m}$ are the bias weights of the output layer. Finally, the response of the net is given as:

$$
\tilde{O}_{m}=\left\lfloor\underline{O}_{m}, \bar{O}_{m}\right\rfloor=\left\lfloor f\left(\underline{Y}_{m}\right), f\left(\bar{Y}_{m}\right)\right\rfloor .
$$

The error value for the present neural network is

$$
\begin{aligned}
\tilde{E} & =\frac{1}{2}\left[\left(\underline{d}_{m}-\underline{O}_{m}\right)^{2}+\left(\bar{d}_{m}-\bar{O}_{m}\right)^{2}\right], \\
m & =1,2, \ldots, M .
\end{aligned}
$$

In order to minimize the cost function, the interval weights $\tilde{v}_{j i}, \tilde{w}_{m j}$ and the interval biases $\tilde{\theta}_{j}, \tilde{\theta}_{m}$ are adjusted. The updating of interval weights is done using the above cost function as below,

$$
\begin{aligned}
\tilde{w}_{m j}^{(N e w)} & =\left[\underline{w}_{m j}^{(N e w)}, \bar{w}_{m j}^{(N e w)}\right] \\
& =\left[\left[\underline{w}_{m j}^{(\text {Old })}, \bar{w}_{m j}^{(\text {Old })}\right]\right]+\left[\Delta \underline{w}_{m j}, \Delta \bar{w}_{m j}\right], \\
m & =1,2, \ldots, M \text { and } j=1,2, \ldots, J
\end{aligned}
$$

where change in weights are

$$
\begin{aligned}
\Delta \tilde{w}_{m j} & =-\eta \frac{\partial \tilde{E}}{\partial \tilde{w}_{m j}}=\left[\Delta \underline{w}_{m j}, \Delta \bar{w}_{m j}\right] \\
& =\left[-\eta \frac{\partial \tilde{E}}{\partial \underline{w}_{m j}},-\eta \frac{\partial \tilde{E}}{\partial \bar{w}_{m j}}\right], \\
m & =1,2, \ldots, M \text { and } j=1,2, \ldots, J .
\end{aligned}
$$




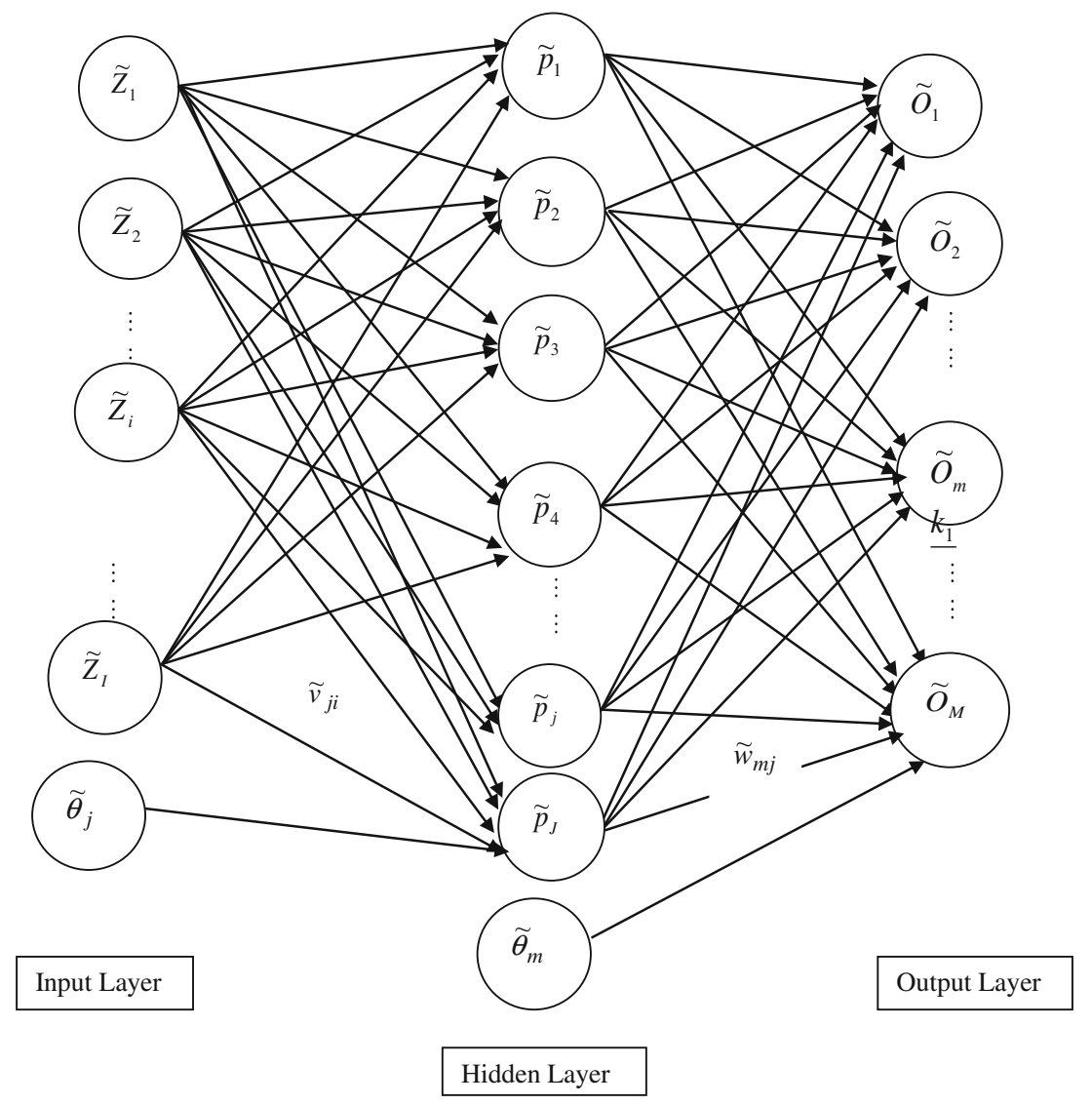

Figure 1. Feed-forward interval neural network.

And $\eta$ is the learning constant. $\left(\partial \tilde{E} / \partial \tilde{w}_{m j}\right)$ can be derived from equation (5) using equations (3 and 4) as:

$$
\begin{aligned}
\Delta \tilde{w}_{m j} & =\frac{\partial \tilde{E}}{\partial \tilde{w}_{m j}} \\
& =-\eta \times \frac{1}{2}\left\{\left(\tilde{d}_{m}-\tilde{O}_{m}\right) \cdot\left(1-\tilde{O}_{m}^{2}\right)\right\}\left[\tilde{U}_{j}\right]
\end{aligned}
$$

or

$$
\begin{aligned}
\frac{\partial \tilde{E}}{\partial \tilde{w}_{m j}}= & -\eta \times \frac{1}{2}\left\{\left[\underline{d}_{m}, \overline{d_{m}}\right]-\left[\underline{O}_{m}, \bar{O}_{m}\right]\right\} \\
& \times\left\{1-\left[\underline{O}_{m}, \bar{O}_{m}\right]^{2}\right\} \times\left[\underline{U}_{j}, \bar{U}_{j}\right]
\end{aligned}
$$

The above expression cannot be computed easily in case of bipolar activation function as it has to satisfy different condition depending upon various sign (positivity or negativity) of weights and training patterns. The use of bipolar sigmoidal function leads to somewhat complicated interval calculations which make the derivation of back-propagation algorithm very complicated. It is worth mentioning that the expression in case of unipolar (for change in weights) is different and which can easily be handled for interval data. In order to avoid these complicacy, the data are first normalized and transferred to $[0,1]$ by using a transformation which convert the data from $[-1$, 1] to $[0,1]$.

\subsection{Transformation of data from $[-1,1]$ to $[0,1]$}

Here input is ground acceleration and output is the structural response which may be positive and/or negative. As said above, first the normalization is done for both input and output data. Then these normalized data are transformed from $[-1,1]$ to $[0,1]$ by means of the following transformation

$$
\tilde{S}_{m}=\frac{1+\tilde{d}_{m}^{\prime}}{2}
$$

where $\tilde{d}_{m}^{\prime}$ is the normalized output in interval form.

\subsection{Learning algorithm of INN using unipolar activation function}

The inputs vectors here are the interval ground acceleration $\tilde{Z}_{i}=\tilde{\ddot{a}}_{i}=\left[\underline{a}_{i}, \overline{\ddot{a}}_{i}\right]$. The net input to the $j$ th hidden unit in the second layer is calculated as:

$$
\begin{aligned}
\tilde{\text { Net }}_{j} & =\left[\underline{\underline{N e t}}_{j}, \overline{\mathrm{Net}}_{j}\right], \\
\underline{\mathrm{Net}}_{j} & =\sum_{\substack{i=1 \\
\underline{v}_{j i} \geq 0}}^{I} \underline{v}_{j i} \underline{Z}_{i}+\sum_{\substack{i=1 \\
\underline{v}_{j i}<0}}^{I} \underline{v}_{j i} \bar{Z}_{i}+\underline{\theta}_{j}, \\
j & =1,2, \ldots, J \text { and } i=1,2, \ldots, I,
\end{aligned}
$$




$$
\overline{\operatorname{Net}}_{j}=\sum_{\substack{i=1 \\ \bar{v}_{j i} \geq 0}}^{I} \bar{v}_{j i} \bar{Z}_{i}+\sum_{\substack{i=1 \\ \bar{v}_{j i}<0}}^{I} \bar{v}_{j i} \underline{Z}_{i}+\bar{\theta}_{j},
$$

where $\left\lfloor\underline{\theta}_{j}, \bar{\theta}_{j}\right\rfloor$ are the interval bias weights of the hidden layer.

To calculate hidden and output units, the activation function used here is the unipolar sigmoidal function. Since the unipolar sigmoidal function is a monotonically increasing function, the interval output can be calculated as:

$f\left(\mathrm{Ne}_{j}\right)=f\left(\left\lfloor\underline{\mathrm{Net}}_{j}, \overline{\mathrm{Net}}_{j}\right\rfloor\right)=\left\lfloor f\left(\underline{\mathrm{Net}}_{j}\right), f\left(\overline{\mathrm{Net}}_{j}\right)\right\rfloor$,

where $f$ is the unipolar sigmoidal function defined by

$$
f(\mathrm{Ne} \tilde{\mathrm{t}})=\frac{1}{1+\exp (-\gamma \mathrm{Ne} \tilde{\mathrm{t}})} .
$$

The output of the hidden unit is then evaluated as:

$$
\tilde{U}_{j}=\left\lfloor\underline{U}_{j}, \bar{U}_{j}\right\rfloor=\left\lfloor f\left(\underline{\mathrm{Net}}_{j}\right), f\left(\overline{\mathrm{Net}}_{j}\right)\right\rfloor
$$

The total net from hidden to the output unit is now calculated as:

$$
\begin{aligned}
\text { Net }_{m} & =\left[\underline{\operatorname{Net}}_{m}, \overline{\operatorname{Net}}_{m}\right], \\
\text { Net }_{m} & =\sum_{\substack{j=1 \\
\underline{w}_{m j} \geq 0}}^{J} \underline{w}_{m j} \underline{U}_{j}+\sum_{\substack{j=1 \\
\underline{w}_{m j}<0}}^{J} \underline{w}_{m j} \bar{U}_{j}+\underline{\theta}_{m}, \\
m & =1,2, \ldots, M \text { and } j=1,2, \ldots, J, \\
\overline{\operatorname{Net}}_{m} & =\sum_{\substack{j=1 \\
\bar{w}_{m j} \geq 0}}^{J} \bar{w}_{m j} \bar{U}_{j}+\sum_{\substack{j=! \\
\bar{w}_{m j}<0}}^{J} \bar{w}_{m j} \underline{U}_{j}+\bar{\theta}_{m},
\end{aligned}
$$

where $\left[\underline{\theta}_{m}, \bar{\theta}_{m}\right]$ are the bias weights of the output layer. Finally, the response of the net is given as $\tilde{O}_{m}=\left\lfloor\underline{O}_{m}, \bar{O}_{m}\right\rfloor=\left\lfloor f\left(\underline{\mathrm{Net}}_{m}\right), f\left(\overline{\mathrm{Net}}_{m}\right)\right\rfloor$.

The cost function is to be minimized in the learning algorithm using the desired output and actual output which is defined in Ishibuchi et al. (1993) as:

$$
\tilde{E}=\underline{E}+\bar{E},
$$

where

$$
\begin{aligned}
& \underline{E}=\frac{1}{2}\left(\underline{d}_{m}-\underline{O}_{m}\right)^{2}, \quad m=1,2, \ldots, M, \\
& \bar{E}=\frac{1}{2}\left(\bar{d}_{m}-\bar{O}_{m}\right)^{2}
\end{aligned}
$$

for the present neural network. Using the above cost function, the interval weights between output and hidden layers are updated as in equations (6-7).
Hence, $\left(\partial \tilde{E} / \partial \underline{w}_{m j}\right)$ can be derived from equation (12) using equations (10 and 11) as:

$$
\begin{aligned}
\frac{\partial \tilde{E}}{\partial \underline{w}_{m j}}=\left\{\begin{array}{c}
-\eta \times\left\{\left(\underline{d}_{m}-\underline{O}_{m}\right) \cdot\left(1-\underline{O}_{m}\right) \cdot \underline{O}_{m}\right\} \times\left[\underline{U}_{j}\right], \\
\quad \text { if } \underline{w}_{m j} \geq 0 \\
-\eta \times\left\{\left(\underline{d}_{m}-\underline{O}_{m}\right) \cdot\left(1-\underline{O}_{m}\right) \cdot \underline{O}_{m}\right\} \times\left[\bar{U}_{j}\right] \\
\quad \text { if } \underline{w}_{m j}<0
\end{array}\right. \\
m=1,2, \ldots, M \text { and } j=1,2, \ldots, J .
\end{aligned}
$$

$\left(\partial \tilde{E} / \partial \bar{w}_{m j}\right)$ can be derived as:

$$
\begin{aligned}
\frac{\partial \tilde{E}}{\partial \bar{w}_{m j}}=\left\{\begin{array}{c}
-\eta \times\left\{\left(\bar{d}_{m}-\bar{O}_{m}\right) \cdot\left(1-\bar{O}_{m}\right) \cdot \bar{O}_{m}\right\} \times\left[\bar{U}_{j}\right] \\
\quad \text { if } \bar{w}_{m j} \geq 0 \\
-\eta \times\left\{\left(\bar{d}_{m}-\bar{O}_{m}\right) \cdot\left(1-\bar{O}_{m}\right) \cdot \bar{O}_{m}\right\} \times\left[\underline{U}_{j}\right] \\
\quad \text { if } \bar{w}_{m j}<0
\end{array}\right. \\
m=1,2, \ldots, M \text { and } j=1,2, \ldots, J
\end{aligned}
$$

The above expression can be easily handled now. The interval weights $\left(\tilde{v}_{j i}\right)$ between the hidden and input layers can be computed as:

$$
\begin{aligned}
\tilde{v}_{j i}^{(\text {New })} & =\left[\underline{v}_{j i}^{(\text {New })}, \bar{v}_{j i}^{(\text {New })}\right] \\
& =\left[\left[\underline{v}_{j i}^{(\text {Old })}, \bar{v}_{j i}^{(\text {Old })}\right]\right]+\left[\Delta \underline{v}_{j i}, \Delta \bar{v}_{j i}\right], \\
j & =1,2, \ldots, J \text { and } i=1,2, \ldots, I,
\end{aligned}
$$

where the change in weights are

$$
\begin{aligned}
\Delta \tilde{v}_{j i} & =\left[\Delta \underline{v}_{j i}, \Delta \bar{v}_{j i}\right] \\
& =\left[-\eta \frac{\partial \tilde{E}}{\partial \underline{v}_{j i}},-\eta \frac{\partial \tilde{E}}{\partial \bar{v}_{j i}}\right], \\
j & =1,2, \ldots, J \text { and } i=1,2, \ldots, I .
\end{aligned}
$$

While modifying $\underline{v}_{j i}, \bar{v}_{j i}$ and $\underline{w}_{m j}, \bar{w}_{m j}$ by equations (13-16), it is undesirable, but possible sometimes that $\underline{v}_{j i}>\bar{v}_{j i}$ and $\underline{w}_{m j}>\bar{w}_{m j}$. In order to cope with this situation, the interval weights from input to hidden layer and from hidden to output layer are determined as:

$$
\begin{aligned}
v_{j i}^{(N e w)}= & \left\lfloor\min \left\{\underline{v}_{j i}^{(N e w)}, \bar{v}_{j i}^{(N e w)}\right\},\right. \\
& \left.\max \left\{\underline{v}_{j i}^{(N e w)}, \bar{v}_{j i}^{(N e w)}\right\}\right\rfloor, \\
w_{m j}^{(N e w)}= & \left\lfloor\min \left\{\underline{w}_{m j}^{(N e w)}, \bar{w}_{m j}^{(N e w)}\right\},\right. \\
& \left.\max \left\{\underline{w}_{m j}^{(N e w)}, \bar{w}_{m j}^{(N e w)}\right\}\right\rfloor .
\end{aligned}
$$

In the similar fashion, the interval biases $\tilde{\theta}_{j}$ and $\tilde{\theta}_{m}$ are also updated. 
3.4 Transformation of data from $[0,1]$ to $[-1,1]$ by inverse transformation

Once training is done, the data are again transferred back to its bipolar form, i.e., $[-1,1]$ by using inverse transformation. The product of inverse transformation and the normalization factor gives the INN results in its bipolar form. After back propagation training is completed, the final INN output is calculated as:

$$
\tilde{O}_{m}=\tilde{R}_{m} \cdot \tilde{l}
$$

where $\tilde{R}_{m}=2 \cdot \tilde{S}_{m}-1, \tilde{O}_{m}$ are the final INN outputs, $\tilde{R}_{m}$ is the inverse transformation and $\tilde{l}$ is the normalizing factor in interval form.

\section{Response analysis of multi-degree of freedom system subject to ground motion}

The basic concept behind the proposed methodology is to predict the interval structural response of multi-degree of freedom system, viz., two, six and ten storey shear buildings subject to various earthquake accelerations by training the same for one particular earthquake data. When a shear building with $n$ storey is subjected to base excitation, then the governing equation of motion in interval form may be written as:

$[\tilde{M}]\left\{\tilde{\ddot{x}}(t)+[\tilde{C}]\{\tilde{\tilde{x}}(t)\}+[\tilde{K}]\{\tilde{x}(t)\}=-[\tilde{M}]\{\psi\} \tilde{\ddot{x}}_{g}(t)\right.$

where $[\tilde{M}]=\lfloor\underline{M}, \bar{M}\rfloor$ is $n \times n$ interval mass matrix, $[\tilde{K}]=\lfloor\underline{K}, \bar{K}\rfloor$ is $n \times n$ interval stiffness matrix of the structure in interval form and $[\tilde{C}]=\lfloor\underline{C}, \bar{C}\rfloor$ represents $n \times n$ interval damping matrix, $\{\psi\}$ is the influence coefficient vector. Here, $\{\tilde{x}(t)\}$ is the displacement relative to the ground, $\{\tilde{\ddot{x}}(t)\}$ is the response acceleration, $\{\tilde{\dot{x}}(t)\}$ is the response velocity and $\tilde{\ddot{x}}_{g}(t)$ is the earthquake ground acceleration, all are in interval form. The global mass, stiffness and damping matrices in interval form can be written as $[\tilde{M}],[\tilde{K}]$ and $[\tilde{C}]$ as below:

$$
\begin{aligned}
& {[\tilde{M}]=\left[\begin{array}{ccccc}
\left.\underline{m}_{1}, \bar{m}_{1}\right] & 0 & \ldots & \ldots & 0 \\
0 & {\left[\underline{m}_{2}, \bar{m}_{2}\right]} & 0 & \cdots & 0 \\
\ldots & \ldots & \ldots & \ldots & \ldots \\
\ldots & \ldots & 0 & {\left[\underline{m}_{n-1}, \bar{m}_{n-1}\right]} & 0 \\
0 & \ldots & \ldots & 0 & {\left[\underline{m}_{n}, \bar{m}_{n}\right]}
\end{array}\right]}
\end{aligned}
$$

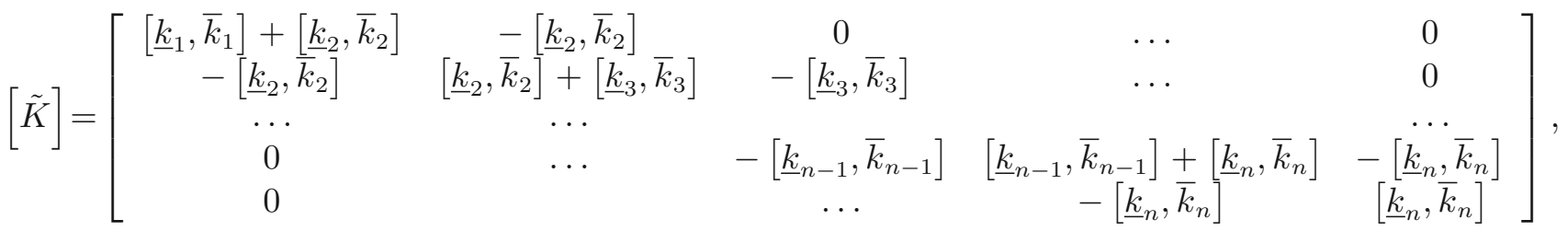

and

$$
[\tilde{C}]=\left[\begin{array}{ccccc}
{\left[\underline{c}_{1}, \bar{c}_{1}\right]+\left[\underline{c}_{2}, \bar{c}_{2}\right]} & -\left[c_{2}, \bar{c}_{2}\right] & 0 & \ldots & 0 \\
-\left[\underline{c}_{2}, \bar{c}_{2}\right] & {\left[\underline{c}_{2}, \bar{c}_{2}\right]+\left[\underline{c}_{3}, \bar{c}_{3}\right]} & -\left[\underline{c}_{3}, \bar{c}_{3}\right] & \ldots & 0 \\
\ldots & \ldots & \ldots & \ldots & \ldots \\
0 & \ldots & -\left[\underline{c}_{n-1}, \bar{c}_{n-1}\right] & {\left[\underline{c}_{n-1}, \bar{c}_{n-1}\right]+\left[\underline{c}_{n}, \bar{c}_{n}\right]} & -\left[\underline{c}_{n}, \bar{c}_{n}\right] \\
0 & \ldots & -\left[\underline{c}_{n}, \bar{c}_{n}\right] & {\left[\underline{c}_{n}, \bar{c}_{n}\right]}
\end{array}\right] .
$$

Equation (20) is generally a set of $n$-coupled equations. The classical method of solving these equations in the absence of damping is to find the normal modes of oscillations of the homogeneous equation and to determine the normal coordinates.

$$
[\tilde{M}]\{\tilde{\ddot{x}}(t)\}+[\tilde{K}]\{\tilde{x}(t)\}=0 .
$$

Let us take normal coordinates in lower form as $(\{\underline{x}(t)\}=[\underline{A}]\{\underline{y}(t)\})$. We have considered the lower form to avoid complicacy arised due to the interval computation. Hence, we will remove ' $\sim$ ' from all notations and denote the lower and upper forms separately.

Substituting $(\{\underline{x}(t)\}=[\underline{A}]\{\underline{y}(t)\})$ and premultiplying by $[\underline{A}]^{T}$ in Equation $(20)$, we get

$$
\begin{aligned}
& {[\underline{A}]^{T}[\underline{M}][\underline{A}]\{\underline{\ddot{y}}(t)\}+[\underline{A}]^{T}[\underline{C}][\underline{A}]\{\underline{\dot{y}}(t)\}} \\
& \quad+[\underline{A}]^{T}[\underline{K}][\underline{A}]\{\underline{y}(t)\}=-[\underline{A}]^{T}[\underline{M}][\psi] \underline{\ddot{x}}_{g}(t) .
\end{aligned}
$$

The above equation reduces to

$$
\begin{gathered}
{\left[\underline{M}_{m}\right]\{\underline{\ddot{y}}(t)\}+\left[\underline{C}_{d}\right]\{\underline{\dot{y}}(t)\}+\left[\underline{K}_{d}\right]\{\underline{y}(t)\}} \\
=-[\underline{A}]^{T}[\underline{M}][\psi] \underline{\ddot{x}}_{g}(t),
\end{gathered}
$$


where

$[\underline{A}]^{T}[\underline{M}][\underline{A}]=\left[\underline{M}_{m}\right]$ is the generalized mass matrix which is diagonal,

$[\underline{A}]^{T}[\underline{K}][\underline{A}]=\left[\underline{K}_{d}\right]$ is the generalized stiffness matrix which is diagonal,

$[\underline{A}]^{T}[\underline{C}][\underline{A}]=\left[\underline{C}_{d}\right]$ is the damping matrix which is in general not diagonal.

If $[C]$ is proportional to $[M]$ or $[\underline{K}]$ then $[\underline{A}]^{T}[\underline{C}][\underline{A}]$ becomes diagonal. Then we can say that the system has proportional damping and equation (23) becomes completely uncoupled. The above differential equations can be solved as single degree of freedom and the solution can be got easily. After getting $\{\underline{y}(t)\}$ from equation (23), the displacement $\underline{x}_{i}(t)$ of any floor can be obtained by using the equation, $(\{\underline{x}(t)\}=[\underline{A}]\{y(t)\})$.

For a linear system with proportional damping, equation (20) can be solved by modal analysis technique. But for earthquake response analysis, the modal analysis technique becomes more efficient. Thus, equation (20) can be reduced to $n$-modal equations of the form (Chakraverty 2005; Chakraverty et al. 2009)

$$
\begin{gathered}
\underline{\ddot{x}}_{r}(t)+2 \underline{\xi}_{r} \tilde{\omega}_{r} \underline{\dot{x}}_{r}(t)+\underline{\omega}_{r}^{2} \underline{x}_{r}(t)=-\underline{\Gamma}_{r} \underline{\ddot{x}}_{g}(t), \\
r=1,2, \ldots, n,
\end{gathered}
$$

where $n(\leq N)$ is the number of significant modes, $\underline{\xi}_{r}$ is the damping ratio and the modal coordinate $\underline{x}_{r}(t)$ is related to the displacement of the $i$ th mass as follows:

$$
\underline{v}_{i}=\sum_{r=1}^{n} \underline{\Phi}_{i r} \underline{x}_{r}
$$

in which $\underline{\Phi}_{i r}$ is the $i$ th component of the $r$ th mode-shape vector and $\underline{\Gamma}_{r}$ is the modal participation factor. Equation (24) represents the equation of motion of $n \mathrm{SDOF}$ system and the response is obtained from Duhamel integral. The Duhamel integral in lower form is written as:

$$
\begin{aligned}
\underline{x}_{r}(t)=- & \frac{\underline{\Gamma}_{r}}{\underline{\omega}_{D r}} \int_{0}^{t} \underline{\ddot{x}}_{g}(\tau) \exp \left[-\underline{\xi}_{r} \underline{\omega}_{r}(t-\tau)\right] \\
& \times \sin \left[\underline{\omega}_{r}(t-\tau)\right] d \tau .
\end{aligned}
$$

Here, $\underline{\omega}_{D r}=\underline{\omega}_{r} \sqrt{1-\underline{\xi}_{r}^{2}}$, where $\underline{\omega}_{D r}, \underline{\omega}_{r}$ and $\underline{\xi}_{r}$ are damped frequency, free vibration frequency and damping ratio, respectively. The time history response of the $i$ th mass is then determined from equation (24) as:

$$
\underline{v}_{i}(t)=\underline{\phi}_{i 1} \underline{x}_{1}(t)+\underline{\phi}_{i 2} \underline{x}_{2}(t)+\cdots
$$

From this, the floor responses of the multi-storey structures, viz., displacement is obtained in lower form. In a similar manner, we can compute for upper form as well. The INN architecture is constructed, taking ground acceleration in interval form as input and the storey response as output in interval form, obtained from the above solution for each time step. Therefore, the whole network consists of one input layer, one hidden layer with varying nodes and one output layer as shown in figure 1.

\section{Numerical results and discussions}

In the present investigation, examples of two, six and ten storey structures have been considered. The Chamoli earthquake data at Barkot in NE (northeast) direction has been considered for training and different intensities of Uttarkashi earthquakes data at Barkot in NE direction are used for testing different storeys. The original Chamoli earthquake is plotted in figure 2. The peak acceleration value of this Chamoli earthquake is

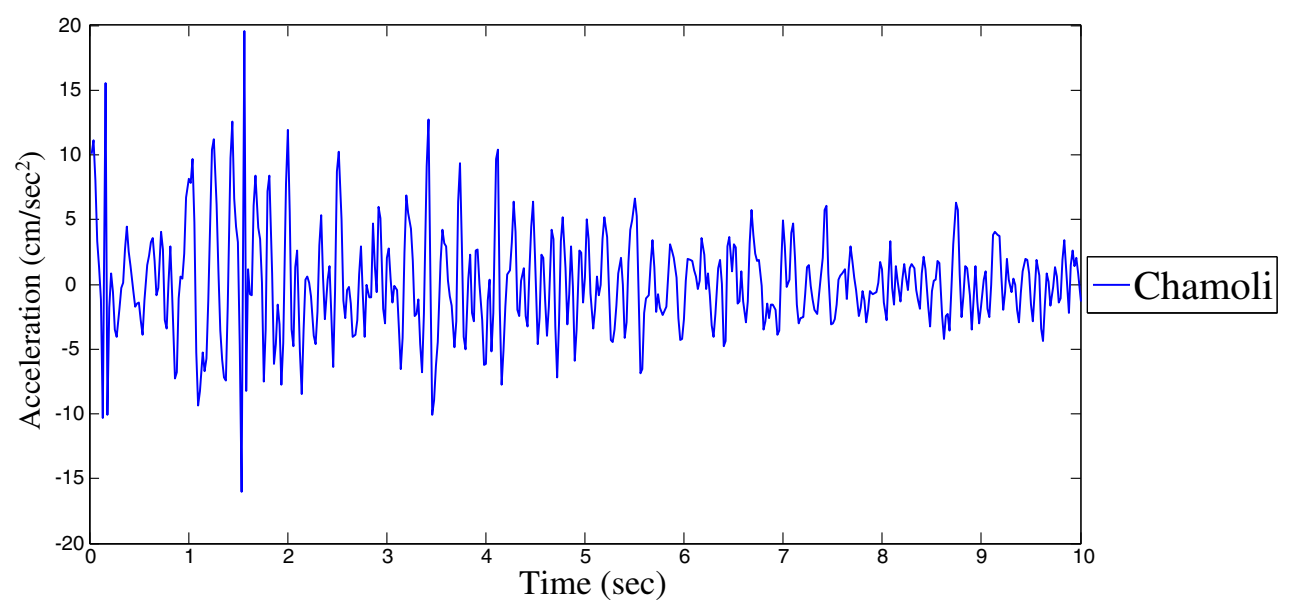

Figure 2. Chamoli earthquake, Barkot, March 29, 1999 peak acceleration: $19.58 \mathrm{~cm} / \mathrm{s}^{2}$. 

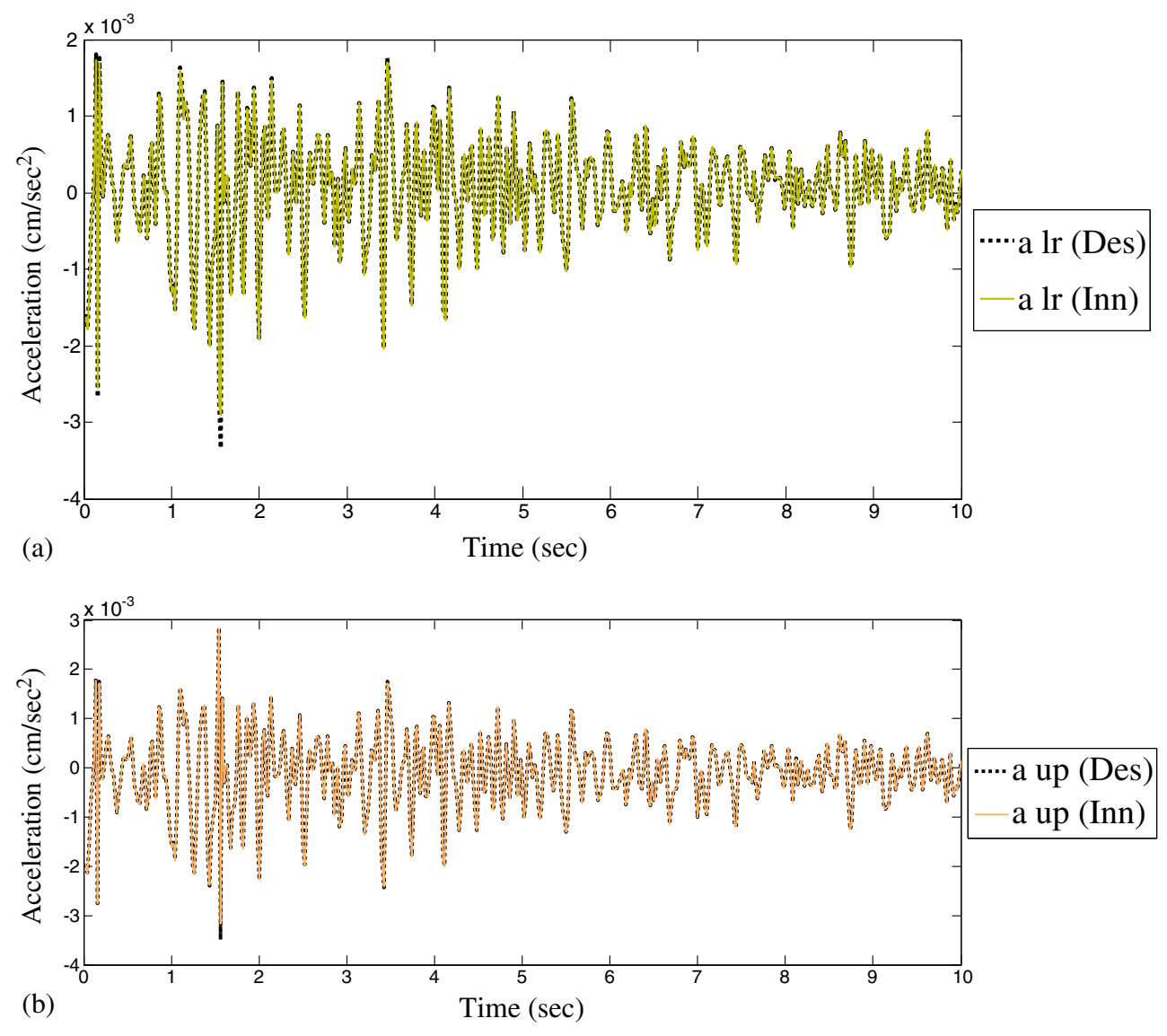

Figure 3. Comparison between the Desired and INN response for (a) lower and (b) upper values of Chamoli earthquake at Barkot (NE) for First-storey (500 data).

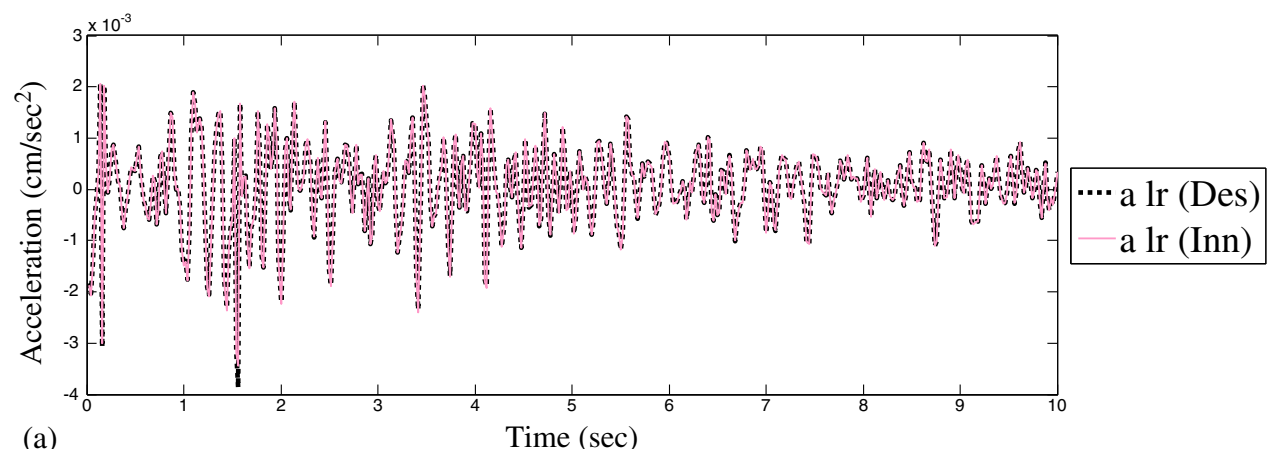

(a)

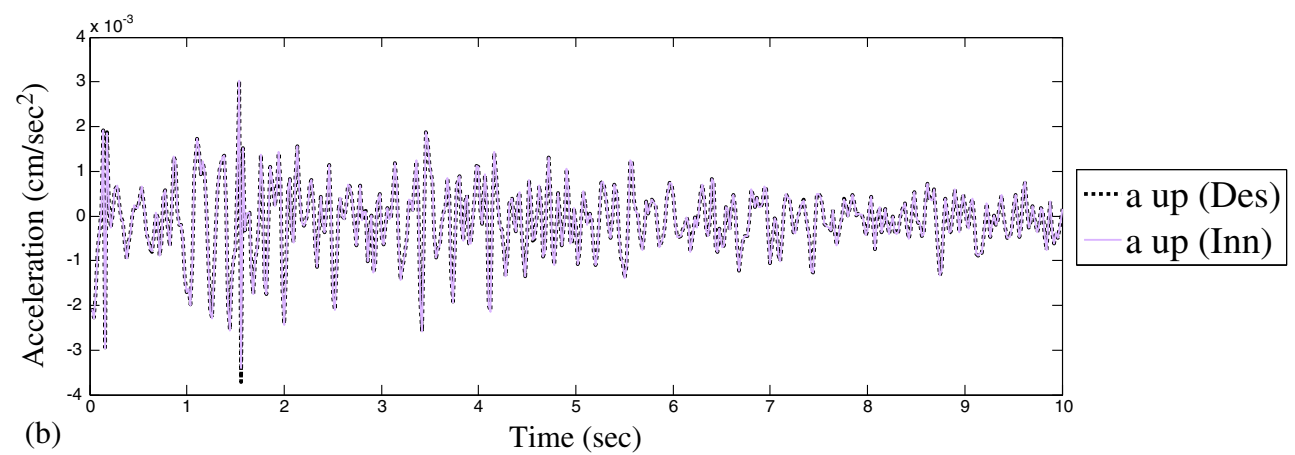

Figure 4. Comparison between the desired and INN response for (a) lower and (b) upper values of Chamoli earthquake at Barkot (NE) for second-storey (500 data). 
$19.58 \mathrm{~cm} / \mathrm{s}^{2}$. As discussed earlier, the earthquake acceleration data have both positive and negative values. A transformation has been used here which converts all the bipolar data to unipolar form. After the data are converted within the range $[0$, 1], the INN algorithm is used and once the training
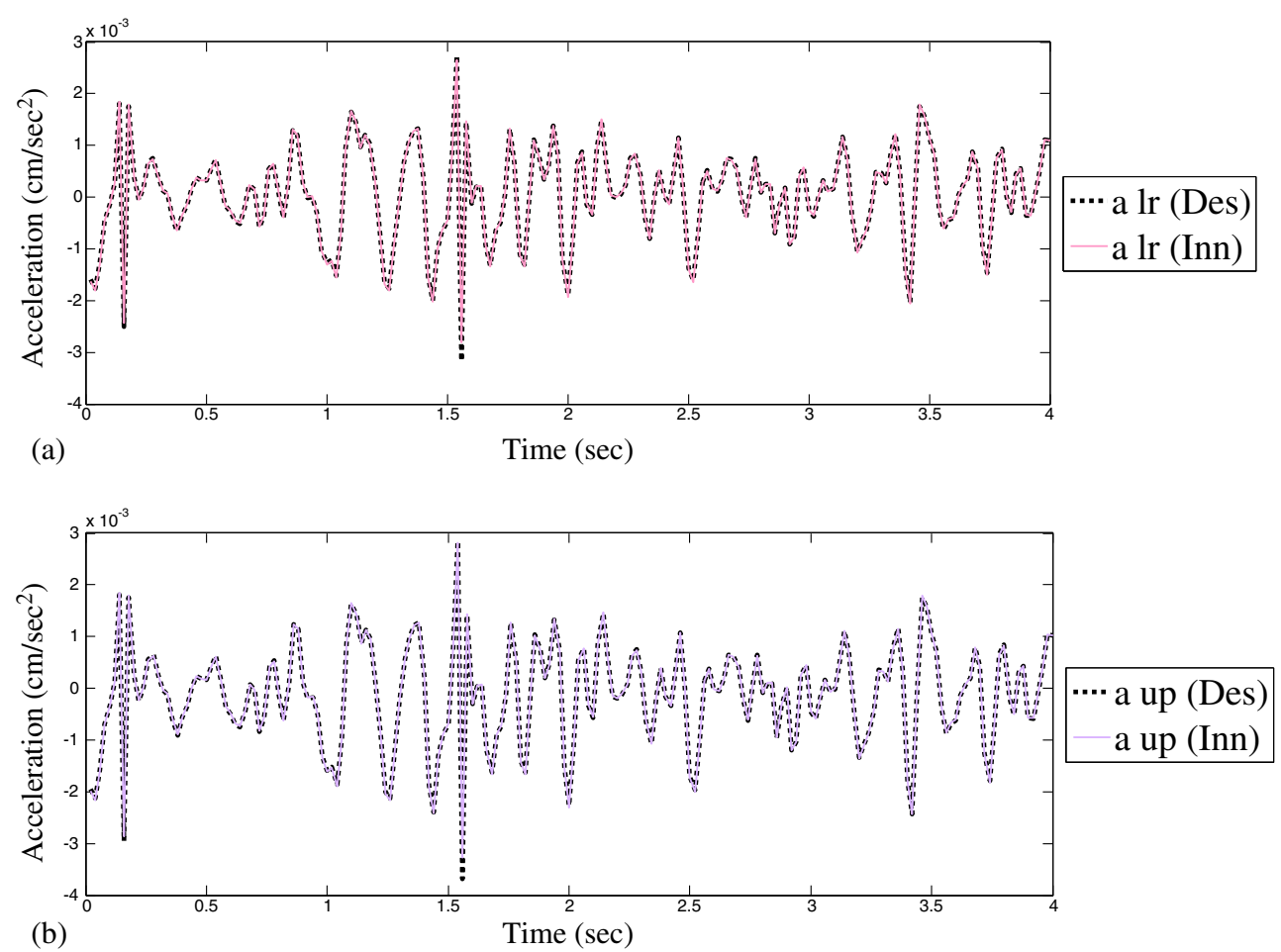

Figure 5. Comparison between the desired and INN response for (a) lower and (b) upper values of Chamoli earthquake at Barkot (NE) for first-storey (200 data).
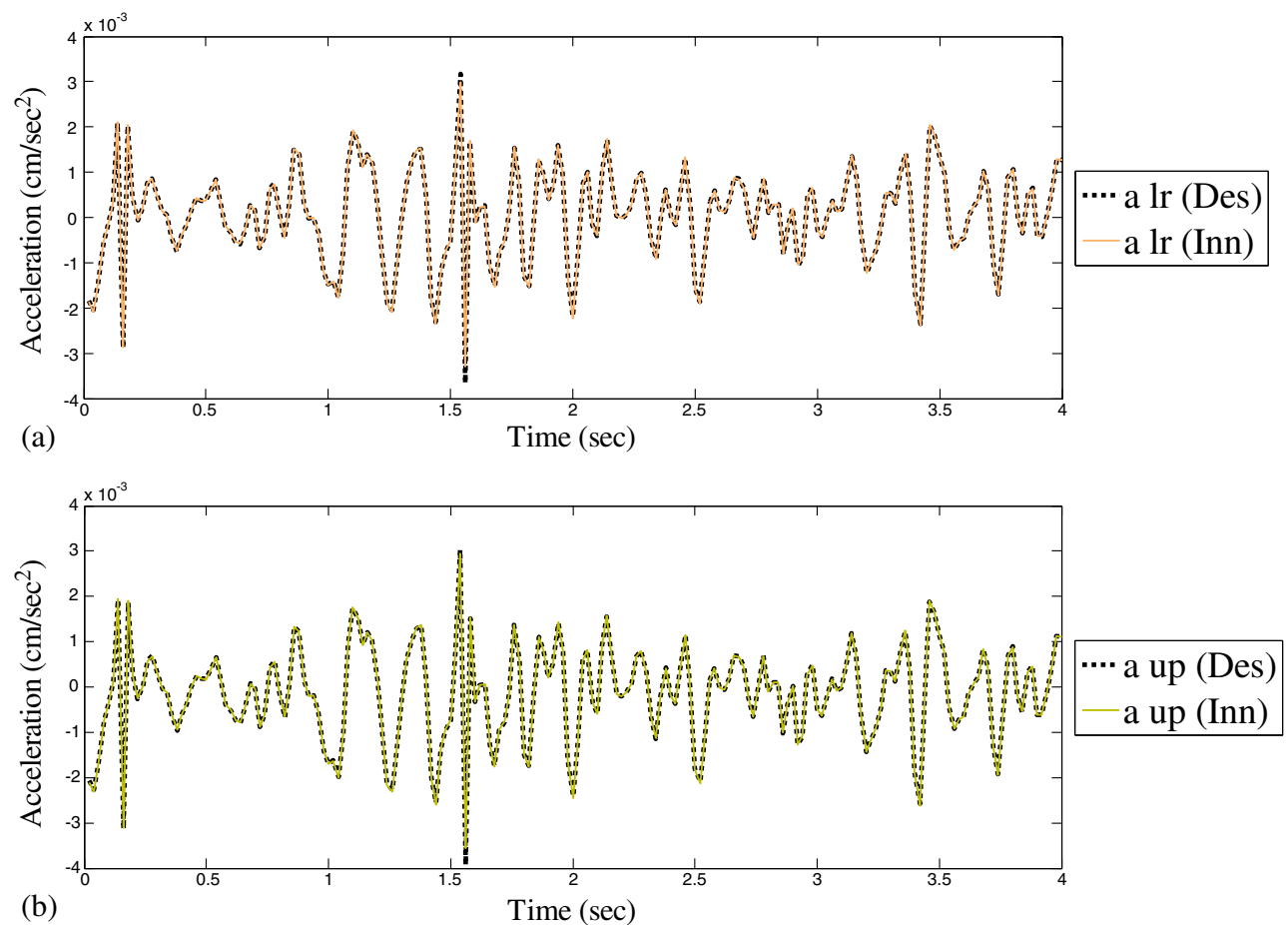

Figure 6. Comparison between the desired and INN response for (a) lower and (b) upper values of Chamoli earthquake at Barkot (NE) for second-storey (200 data). 
is done, again the data are transferred back to its bipolar form by means of the inverse transformation. Interval neural network training is done till a desired accuracy is achieved. The methodology has been discussed by giving the results for following three examples.
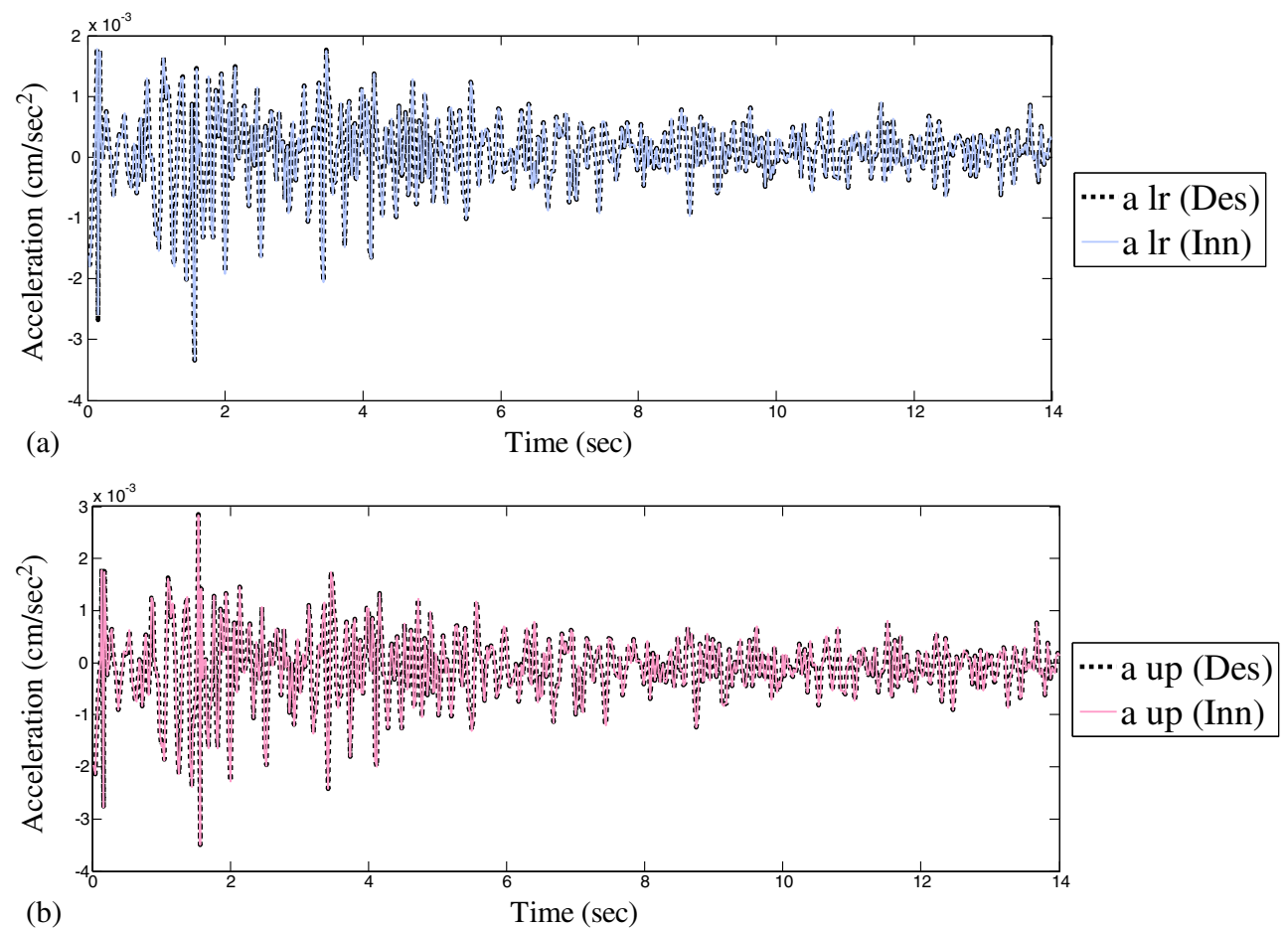

Figure 7. Comparison between the desired and INN response for (a) lower and (b) upper values of Chamoli earthquake at Barkot (NE) for first-storey (700 data).

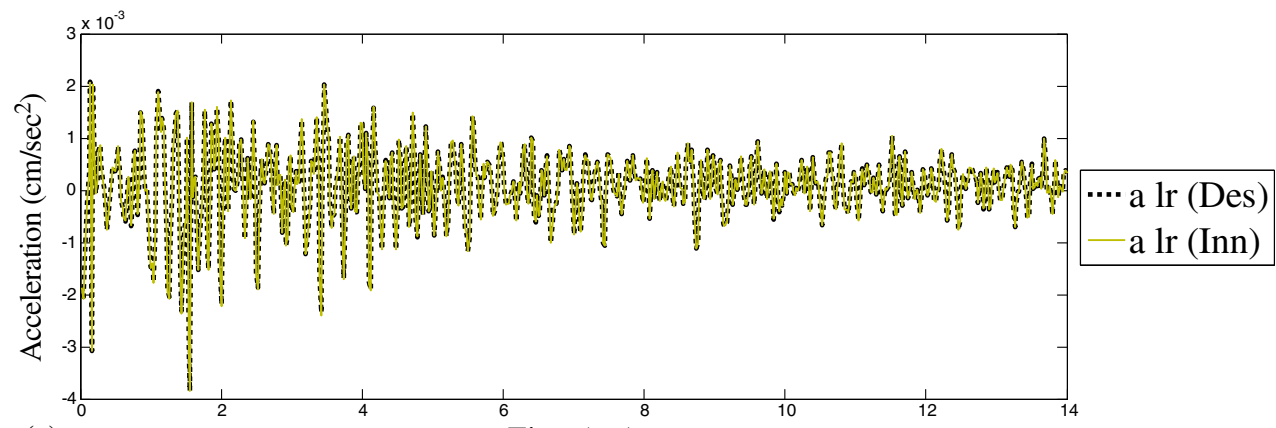

(a)

Time (sec)

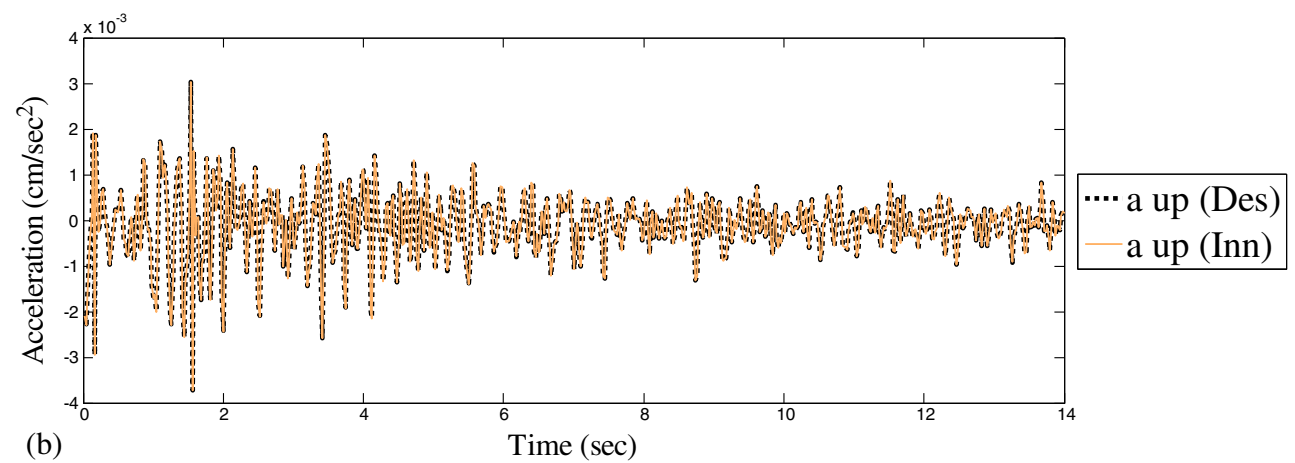

Figure 8. Comparison between the desired and INN response for (a) lower and (b) upper values of Chamoli earthquake at Barkot (NE) for second-storey (700 data). 


\subsection{Two-storey shear buildings}

In the present investigation, an example of two-storey structure (2DOF system) with natural frequency parameters $[23.08,39.58]$ and $[60.22,103.30]$ in interval form has been considered. The damping ratio in interval form is assumed as [8\%, 10\%] critical. Here, the Chamoli earthquake at
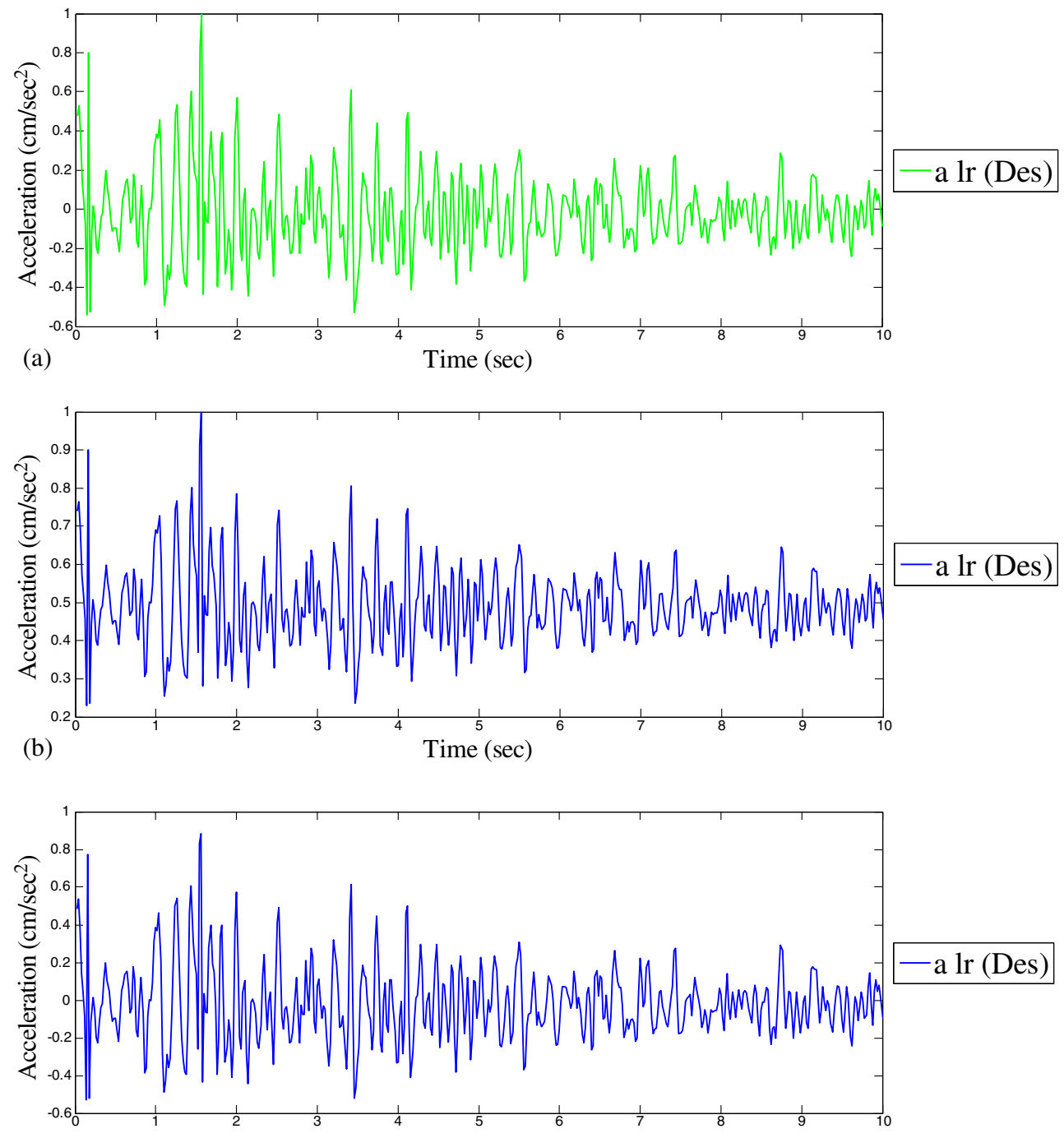

(c)

Time (sec)

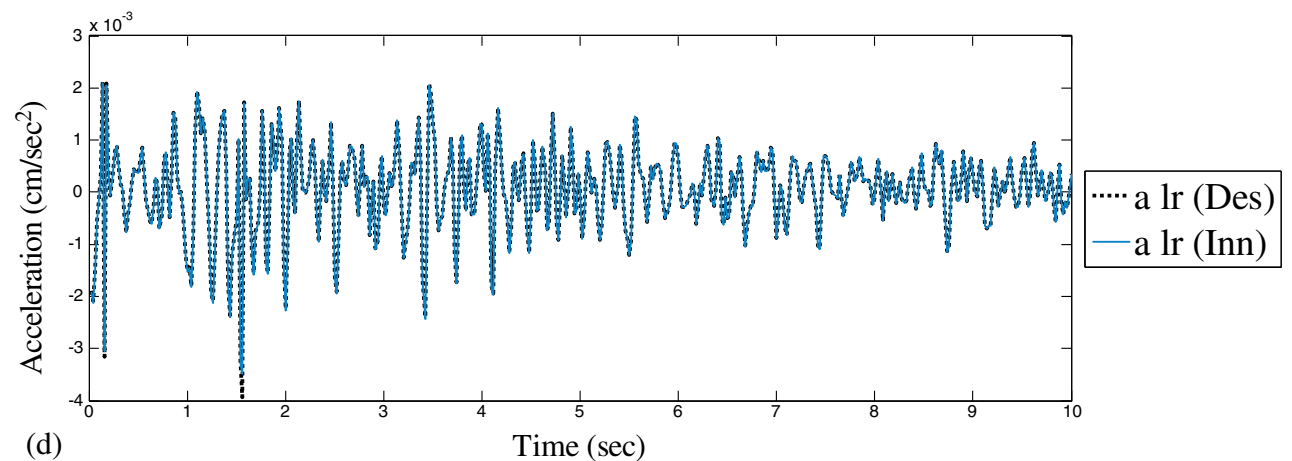

Figure 9. (a) Lower values response of Chamoli earthquake at Barkot (NE) within [-1, 1] range. Conversion of lower values response of Chamoli earthquake at Barkot (NE) within $[0,1]$ range by (b) transformation and (c) inverse transformation. (d) Comparison between the desired and INN response for lower values of Chamoli earthquake at Barkot (NE) for sixthstorey. (e) Upper values response of Chamoli earthquake at Barkot (NE) within [-1, 1] range. (f) Conversion of upper values response of Chamoli earthquake at Barkot $(\mathrm{NE})$ within $[0,1]$ range by transformation. (g) Conversion of upper values response of Chamoli earthquake at Barkot (NE) within $[-1,1]$ range by inverse transformation. (h) Comparison between the desired and INN response for upper values of Chamoli earthquake at Barkot (NE) for sixth-storey. 

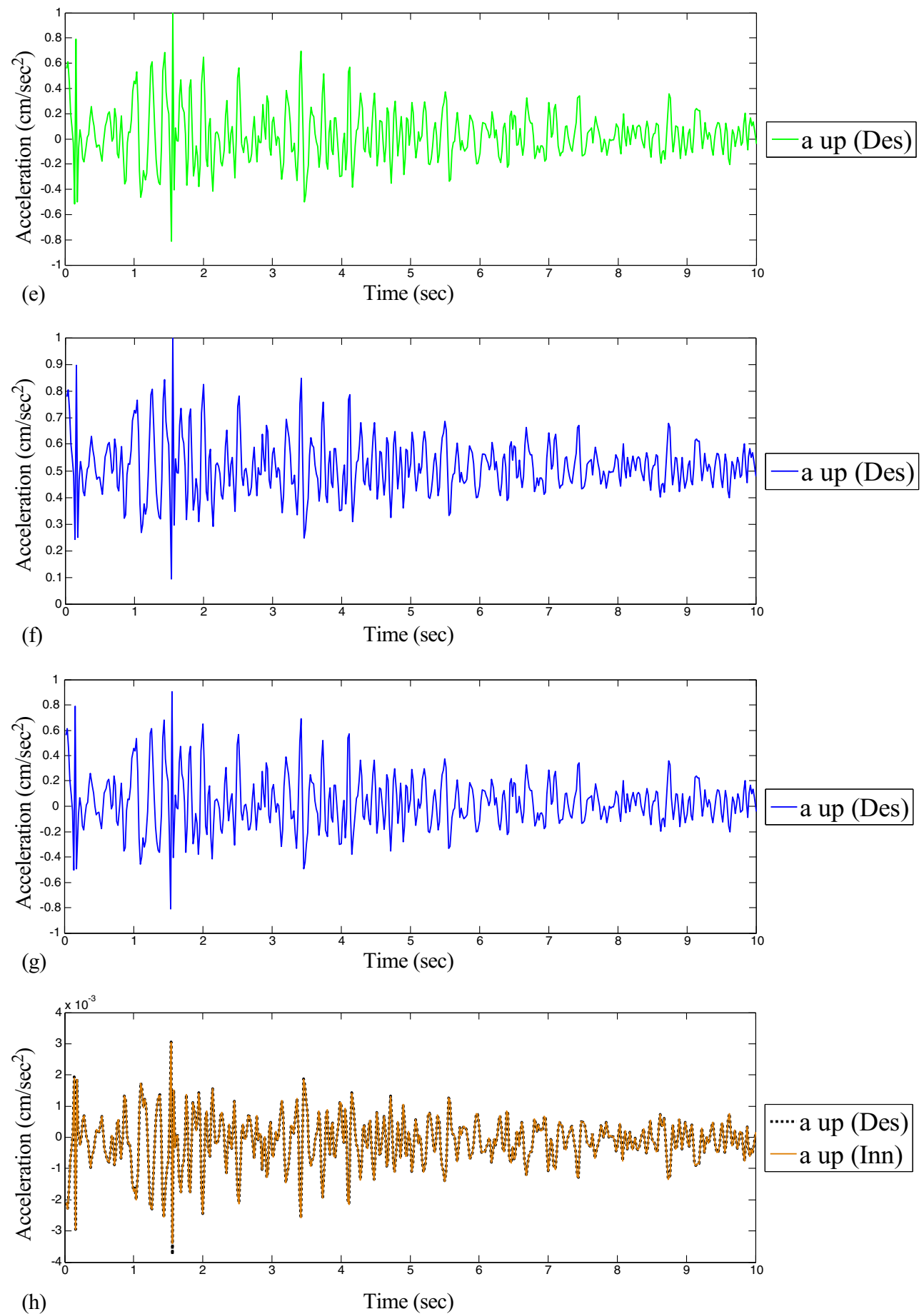

Figure 9. (Continued.)

Barkot (NE direction) has been considered for training with peak values as $[19.08,20.08]$. The responses of the first and second storeys are obtained numerically by solving the Duhamel integral, considering the ground acceleration of Chamoli earthquake at Barkot (NE). Training is done by INN using the ground acceleration and responses of the two storeys in interval form. This training was done for a total time range of $0-10 \mathrm{~s}$
(500 data points, earthquake period) till desired accuracy reached as 0.001. After training, the converged weights are stored for testing. The desired and INN results of first-storey are shown in figure $3(\mathrm{a}-\mathrm{b})$. Figure $4(\mathrm{a}-\mathrm{b})$ shows the comparison between the neural and desired of second-storey. The training is also done for time range of $0-4 \mathrm{~s}$ (200 data) and for a time range of $0-14$ s (700 data). The plot for 200 data points for first storey 
is shown in figure $5(\mathrm{a}-\mathrm{b})$ and for second storey in figure 6(a-b). Similarly, the plots with 700 data points are shown in figure $7(\mathrm{a}-\mathrm{b})$ for first storey and in figure $8(a-b)$ for second storey.

\subsection{Six-storey shear buildings}

Here, the damping ratio in interval form is assumed as $[4 \%, 6 \%]$ critical. The Chamoli earthquake at

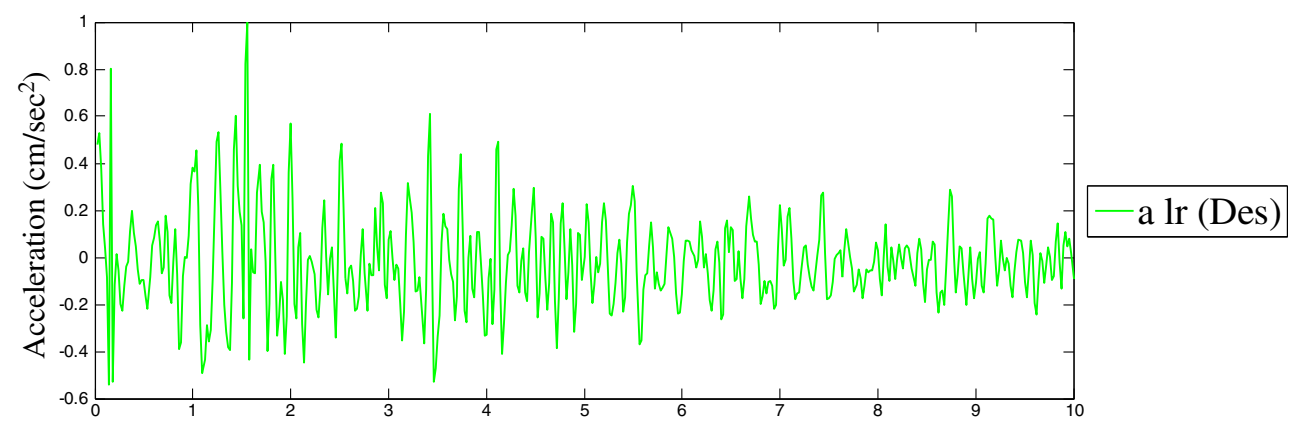

(a)

Time (sec)
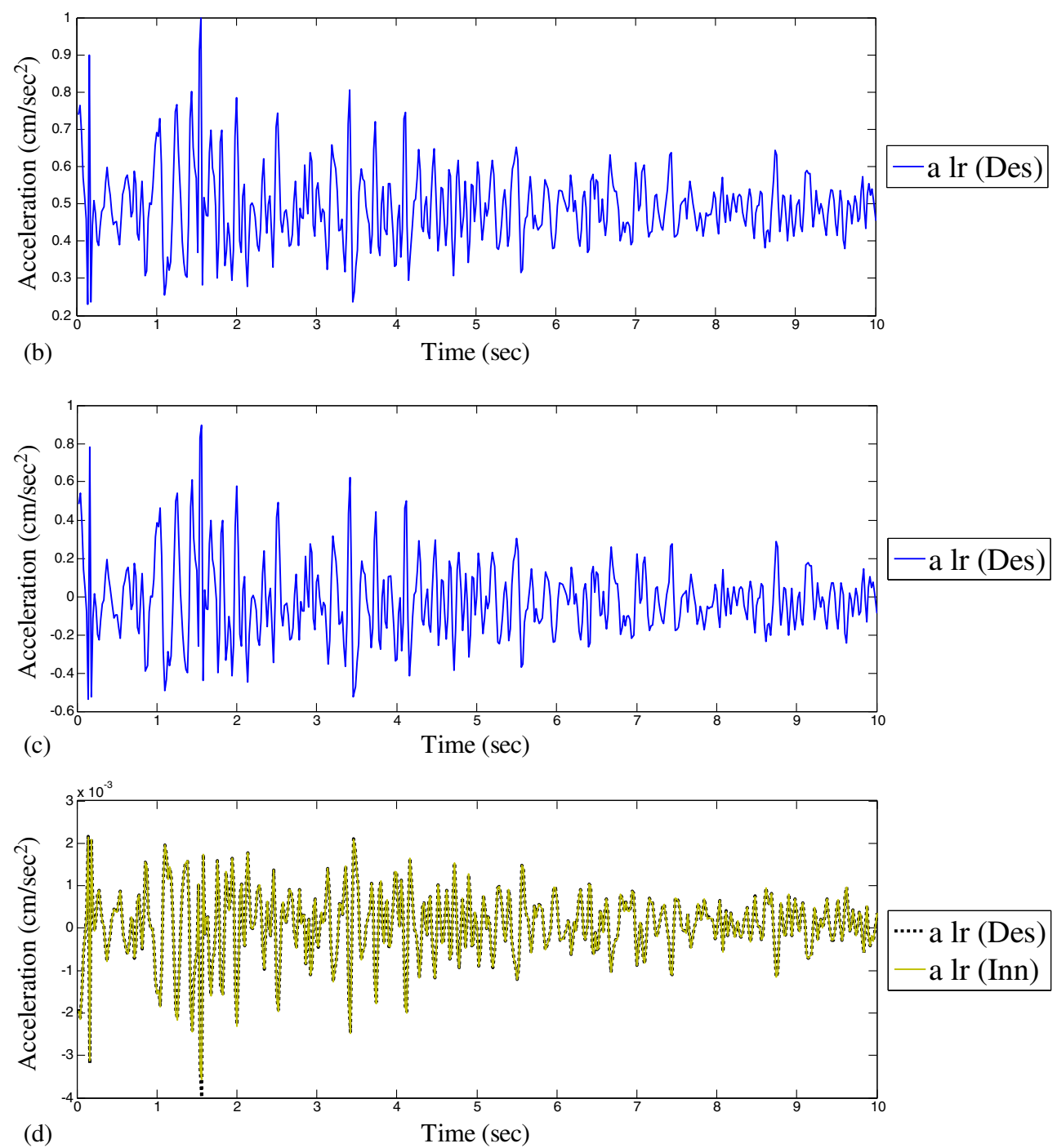

Figure 10. (a) Lower values response of Chamoli earthquake at Barkot (NE) within $[-1,1]$ range. (b) Conversion of lower values response of Chamoli earthquake at Barkot (NE) within [0,1] range by transformation. (c) Conversion of lower values response of Chamoli earthquake at Barkot (NE) within $[-1,1]$ range by inverse transformation. (d) Comparison between the desired and INN response for lower values of Chamoli earthquake at Barkot (NE) for tenth-storey. (e) Upper values response of Chamoli earthquake at Barkot (NE) within $[-1,1]$ range. (f) Conversion of upper values response of Chamoli earthquake at Barkot (NE) within [0,1] range by transformation. (g) Conversion of upper values response of Chamoli earthquake at Barkot (NE) within $[-1,1]$ range by inverse transformation. (h) Comparison between the desired and INN response for upper values of Chamoli earthquake at Barkot (NE) for tenth-storey. 

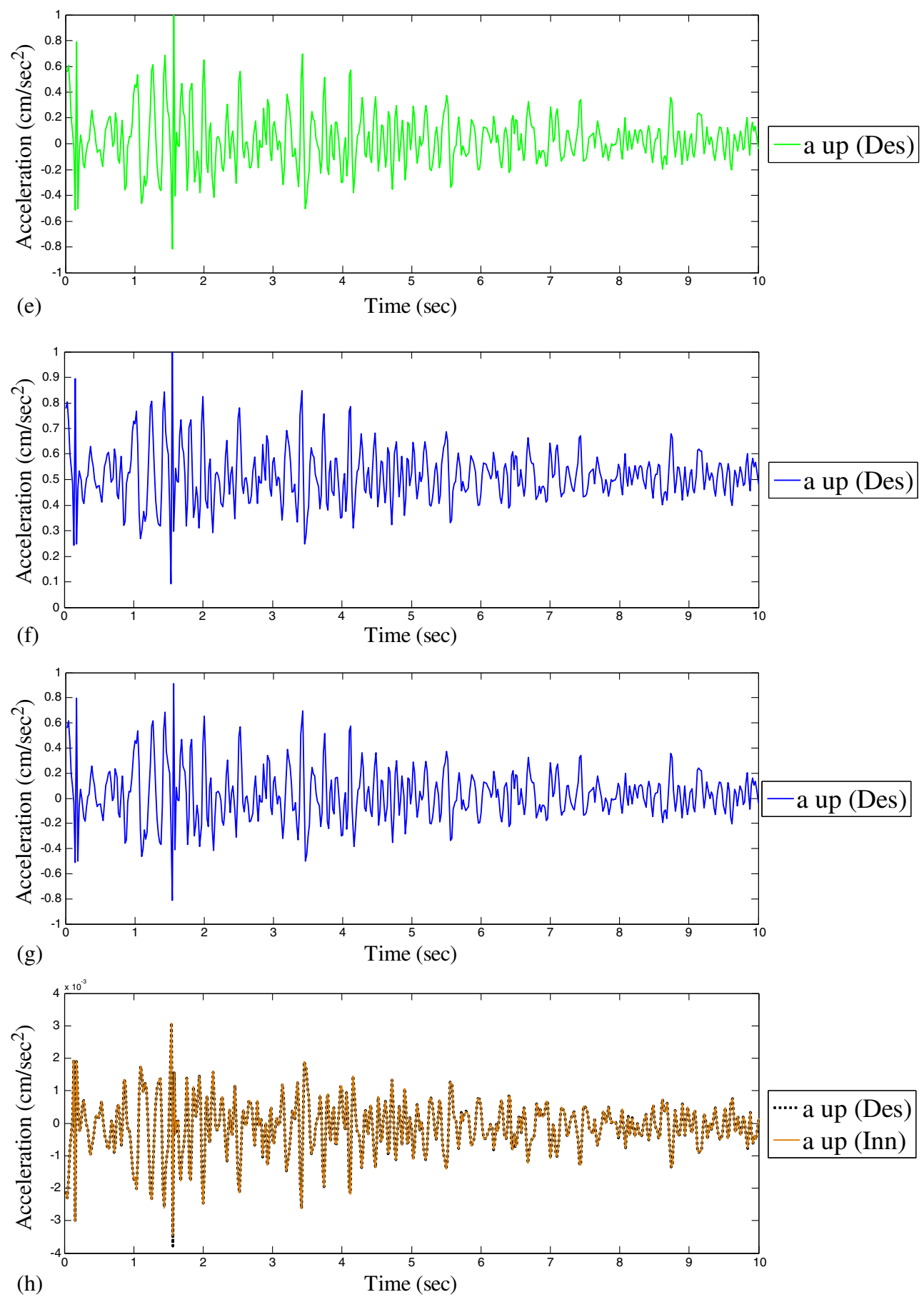

Figure 10. (Continued.)

Barkot (NE) direction has been considered here for training. The training is done in a similar way as done in section 5.1. This training was done for a total time range of $0-10 \mathrm{~s}$ (500 points, earthquake period) with a desired accuracy of 0.001 . After training, the converged weights are stored. The neural and desired results obtained after training for sixth-storey of the building are shown in figure $9(\mathrm{a}-\mathrm{h})$. Figure $9(\mathrm{a})$ shows the data of lower values in $[-1,1]$ range, $9(\mathrm{~b})$ shows conversion of the same data from $[-1,1]$ to $[0,1]$ using the transformation and $9(\mathrm{c})$ shows the conversion of data from $[0,1]$ to $[-1,1]$ using the inverse transformation. Finally, the result comparison between the desired and INN is shown in figure 9(d). For upper value, the results are plotted in figure 9 $(\mathrm{e}-\mathrm{h})$.

\subsection{Ten-storey shear buildings}

The damping ratio in interval form is assumed here as $[8 \%, 10 \%]$ critical for all natural modes for 
the entire storey. In a similar manner, using same earthquake data as in case sections 5.1 and 5.2, the training has been done for ten-storey shear building and the converged weights are stored for testing.
The neural and desired results obtained after training for tenth-storey of the structure are shown in figure 10(a-h). Figure 10(a) shows the data of lower case in $[-1,1]$ range, $10(\mathrm{~b})$ shows conversion of the

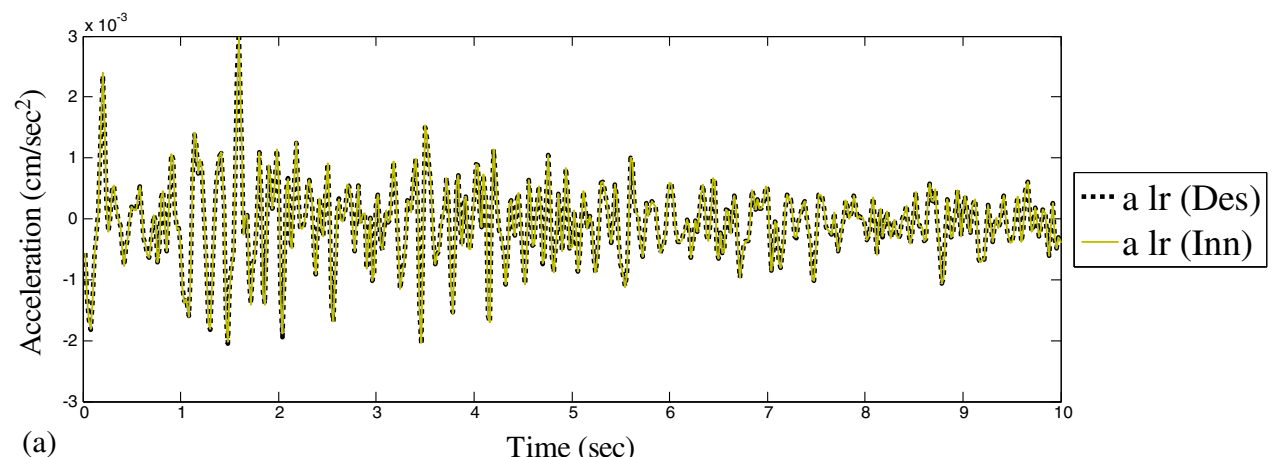

(a)

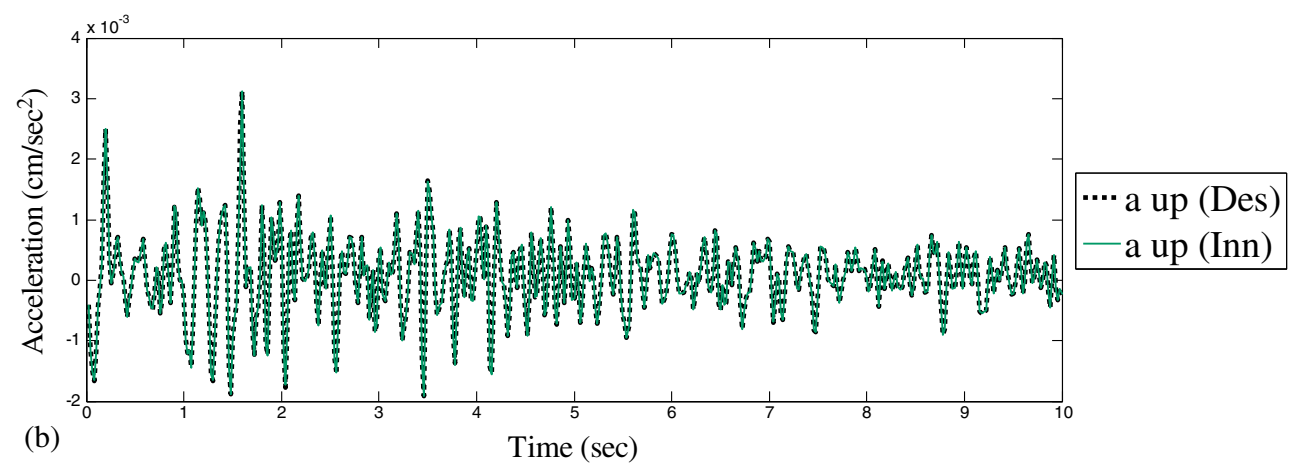

Figure 11. (a) Lower values response comparison and (b) upper values comparison between the desired and INN for $80 \%$ of Uttarkashi earthquake at Barkot (NE) of fourth-storey.
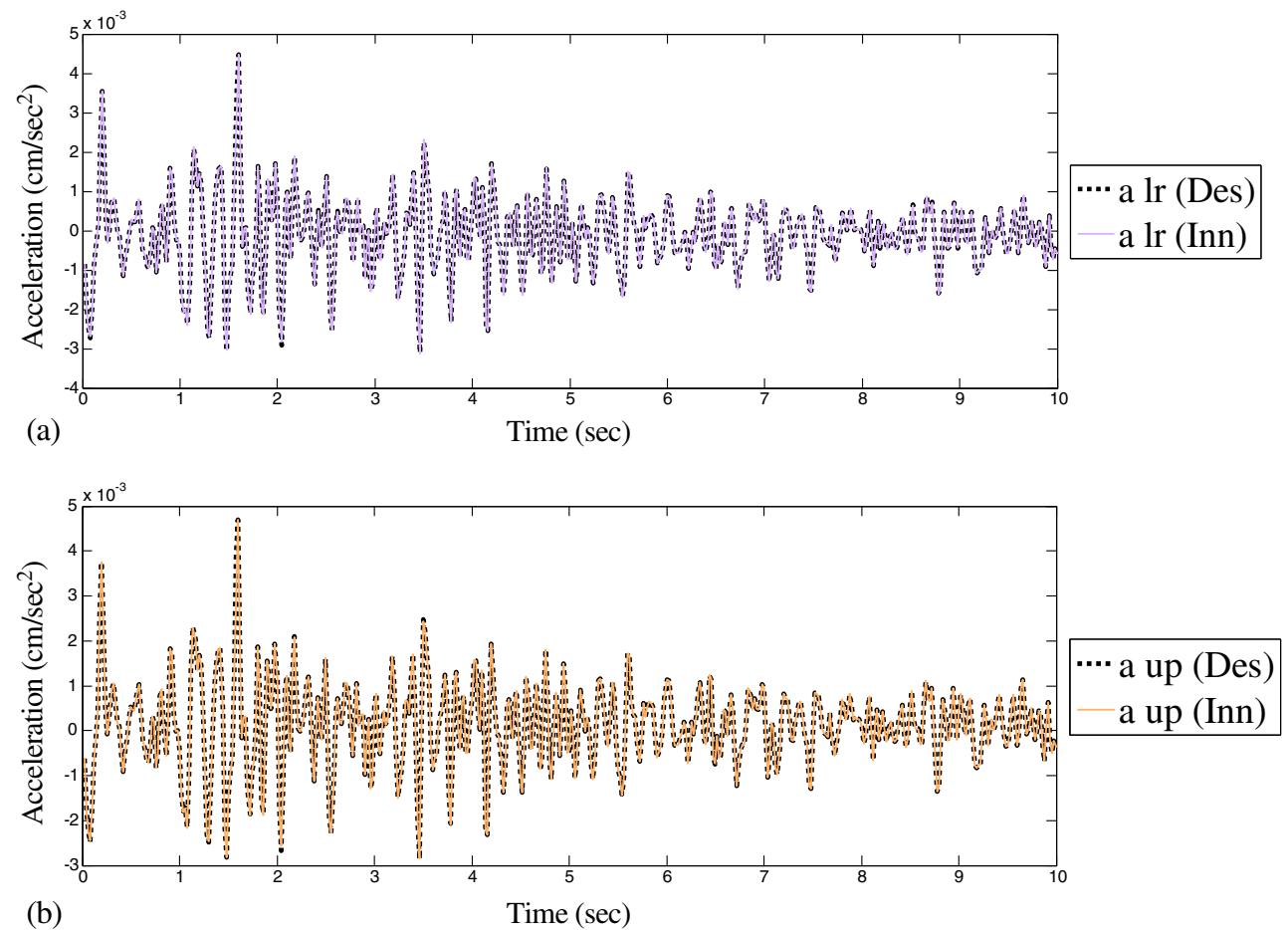

Figure 12. (a) Lower values response comparison and (b) upper values response comparison between the desired and INN for $120 \%$ of Uttarkashi earthquake at Barkot (NE) of fourth-storey. 
same data from $[-1,1]$ to $[0,1]$ using the transformation, 10(c) shows the conversion of data from $[0,1]$ to $[-1,1]$ using the inverse transformation.
Finally, the result comparison between the desired and INN is shown in figure $10(\mathrm{~d})$. For upper value, the figures are plotted in figure $10(\mathrm{e}-\mathrm{h})$.
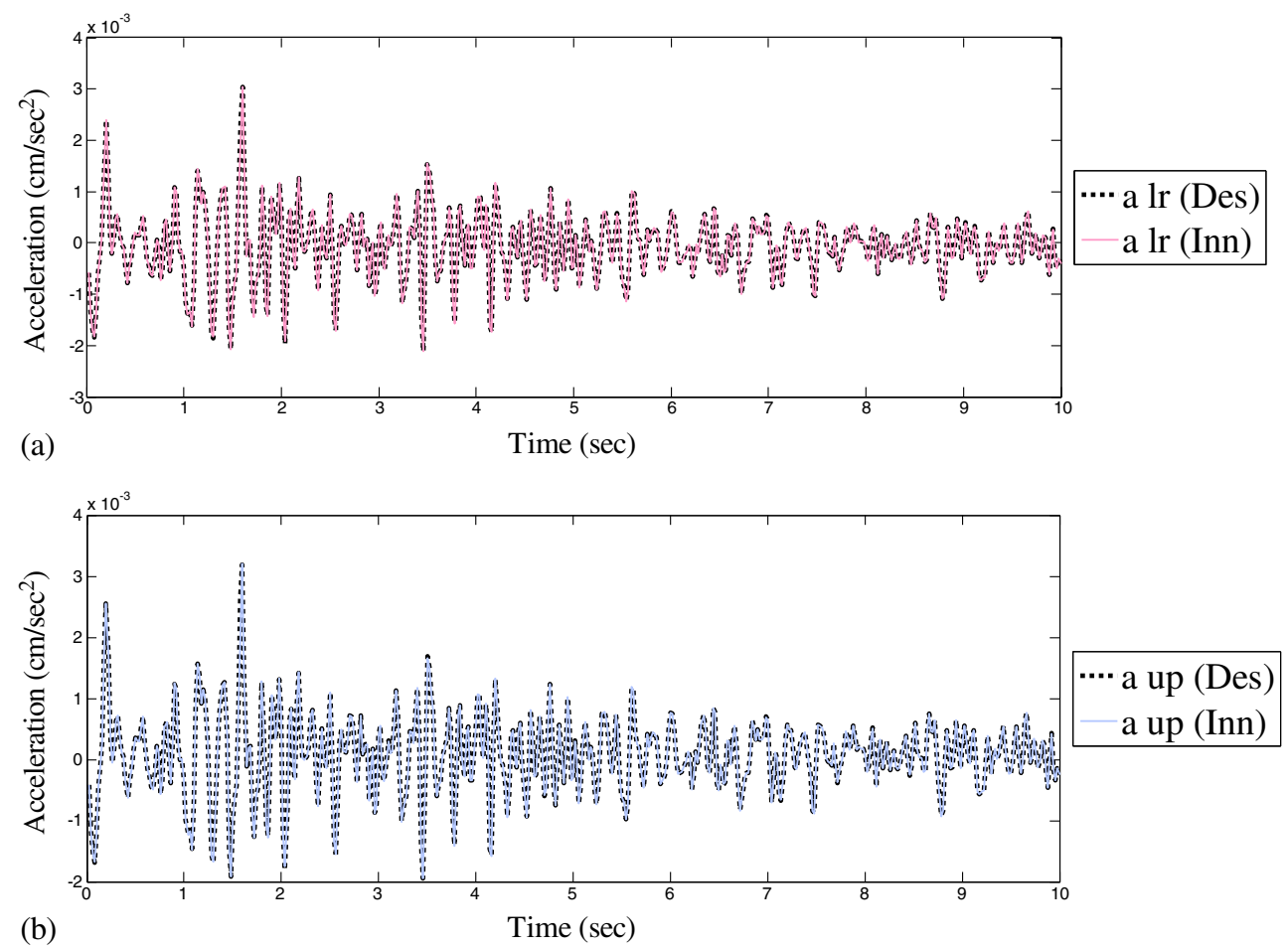

Figure 13. (a) Lower values response comparison and (b) upper values response comparison between the desired and INN for $80 \%$ of Uttarkashi earthquake at Barkot (NE) of ninth-storey.
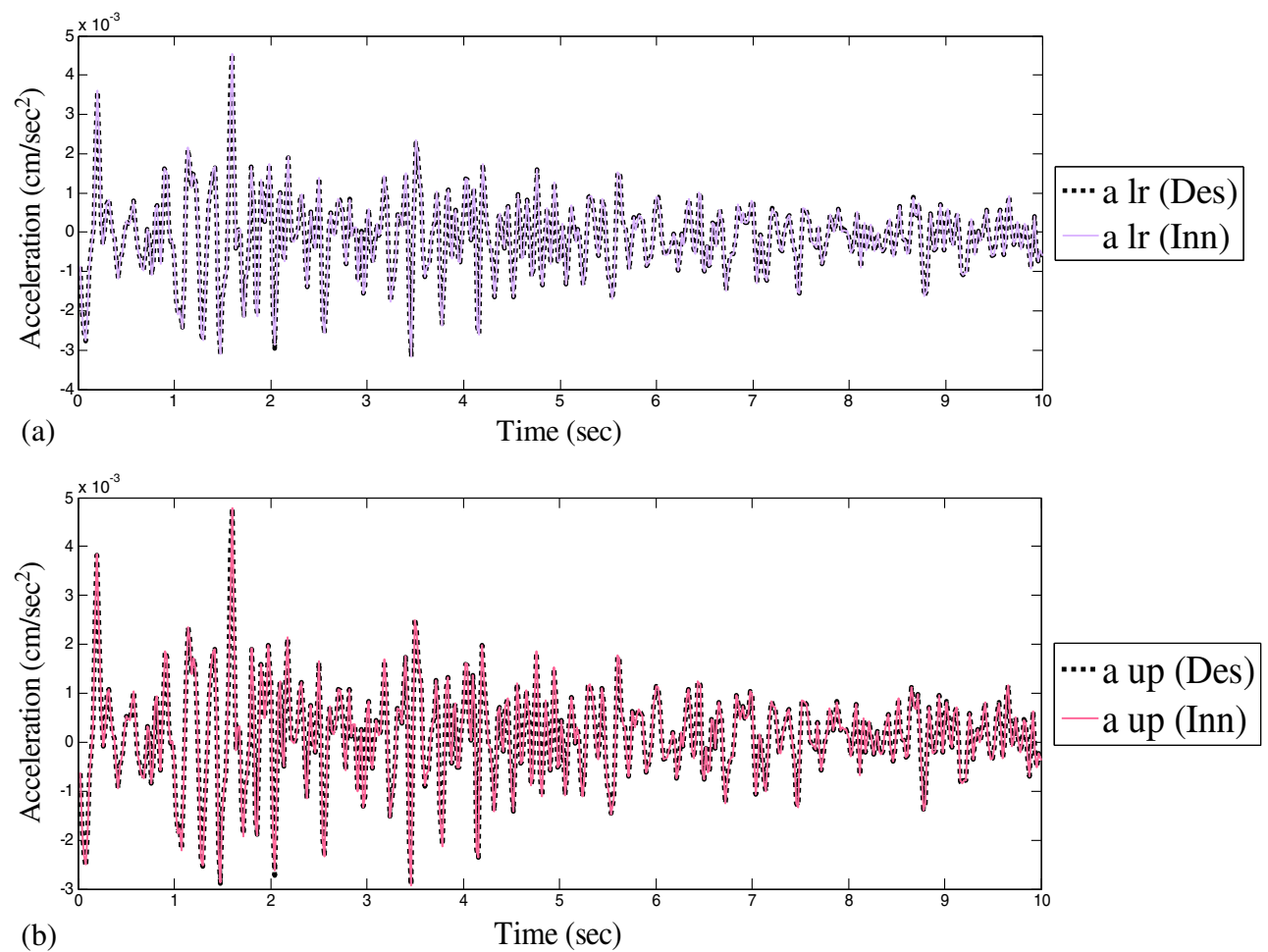

Figure 14. (a) Lower values response comparison and (b) upper values response comparison between the desired and INN for $120 \%$ of Uttarkashi earthquake at Barkot (NE) of ninth-storey. 
Table 1. Comparison between the desired and INN peak acceleration values (testing values).

\begin{tabular}{|c|c|c|c|c|c|c|c|}
\hline \multirow[b]{2}{*}{ Storey } & \multirow[b]{2}{*}{ Intensities } & \multicolumn{3}{|c|}{ Lower peak value $\left(\mathrm{cm} / \mathrm{s}^{2}\right)$} & \multicolumn{3}{|c|}{ Upper peak value $\left(\mathrm{cm} / \mathrm{s}^{2}\right)$} \\
\hline & & Desired & INN & $\begin{array}{c}\text { Error } \\
(\%)\end{array}$ & Desired & INN & $\begin{array}{c}\text { Error } \\
(\%)\end{array}$ \\
\hline 4th storey (Uttarkashi & $80 \%$ & 0.0029843 & 0.0029884 & -0.001 & 0.0031291 & 0.0031282 & 0.000 \\
\hline at Barkot NE) & $120 \%$ & 0.0044764 & 0.0044761 & 0.000 & 0.0046937 & 0.0046924 & 0.000 \\
\hline 9th storey (Uttarkashi & $80 \%$ & 0.0030329 & 0.0030333 & -0.001 & 0.0031929 & 0.0031974 & -0.000 \\
\hline at Barkot NE) & $120 \%$ & 0.0045493 & 0.0045449 & 0.000 & 0.0047894 & 0.0047811 & 0.001 \\
\hline
\end{tabular}

Next, the stored converged weights are used to predict storey responses with different intensity of earthquakes. The stored weights of problem (section 5.2) are used to predict fourth-storey responses of the sixth-storey for $80 \%$ and $120 \%$ of Uttarkashi earthquake at Barkot (NE). The comparison of the neural and desired responses for $80 \%$ is shown in figure $11(\mathrm{a}-\mathrm{b})$ and for $120 \%$ is plotted in figure $12(\mathrm{a}-\mathrm{b})$. Similarly, the ninth-storey responses of tenth-storey for $80 \%$ and $120 \%$ of Uttarkashi earthquake at Barkot (NE) are found using the converged weights of problem (section 5.3). The neural and desired results for $80 \%$ is shown in figure $13(\mathrm{a}-\mathrm{b})$ and for $120 \%$ is plotted in figure $14(\mathrm{a}-\mathrm{b})$. The error $\%$ between desired and INN peak acceleration values (testing) with various intensities of Uttarkashi earthquake acceleration at Barkot (NE) have been presented in table 1.

The investigation done demonstrates that the developed model can handle the data in interval form. It is easier to use because training by one earthquake data, can very well give an idea of the response prediction subject to other earthquakes. Moreover, the model gives a faster prediction of the responses once it is trained by known earthquake data.

\section{Conclusion}

A method has been proposed here by creating a trained black box in terms of INN containing the characteristics of the multi-storey structure and of the earthquake motion. After training of the INN model, it is shown that the black box can very well predict the dynamic response in interval form for other earthquakes that are not used in the training. One may note that while doing the training, the bipolar data in $[-1,1]$ are converted first to unipolar form $[0,1]$ by means of a transformation and once the training is done again the unipolar data are converted back to its bipolar form by using the inverse transformation. The trained INN architecture is then used to simulate and test the structural response of different floors for various intensity earthquake data. As mentioned in the previous sections that although the simulation is done with numerically generated response data for particular earthquake (experimental) data, but the idea may also be used for actual experimental data of the building response. So, by using the input and output as the ground motion and the floor response, one can train the model. Accordingly, the storey response may be predicted for future earthquakes using the trained model.

\section{Acknowledgements}

The authors would like to thank the anonymous reviewers for their valuable suggestions which helped in improving the contents of this paper.

\section{References}

Alvarez F M, Reyes J, Esteban A M and Escudero C R 2013 Determining the best set of seismicity indicators to predict earthquakes. Two case studies: Chile and the Iberian peninsula; Knowl.-Based Syst. $50198-$ 210.

Chakraverty S 2005 Identification of structural parameters of multistorey shear buildings from modal data; Earthq. Eng. Struct. Dyn. 34 543-554.

Chakraverty S and Sahoo D M 2014 Interval response data based system identification of multi-storey shear building using interval neural network modelling; Comp. Assist. Meth. Eng. Sci. 21(2) 123-140.

Chakraverty S, Marwala T and Gupta P 2006 Response prediction of structural system subject to earthquake motion using artificial neural network; Asian J. Civil Eng. 7(3) 301-308.

Chakraverty S, Gupta P and Sharma S 2009 Neural networkbased simulation for response identification of two-storey shear building subject to earthquake motion; Neural Comput. Appl. 19(3) 367-375.

Chetwynd D, Worden K and Manson G 2006 An application of interval-valued neural networks to a regression problem; Proc. Roy. Soc. A 462(2074) 30973114.

Conte J P and Durrani A J 1994 Seismic response modelling of multi-storey buildings using neural networks; J. Intell. Mater. Syst. Struct. 5 392-402.

Furukawa T, Ito M and Inoue Y 2005 System identification of the base isolated structure by prediction error method using recorded seismic response data under HyogokenNanbu earthquake; 12th World Conference on Earthquake 
Engineering, 30 January-4 February, Auckland, New Zealand 2 1-7.

Garczarczyk Z A 2000 Interval neural networks; IEEE International Symposium on Circuits and Systems, 28-31 May, Geneva, Switzerland, pp. 567-570.

Huang C S, Hung S L, Wen C M and Tu T T 2003 A neural network approach for structural identification and diagnosis of a building from seismic response data; Earthq. Eng. Struct. Dyn. 32(2) 187-206.

Ishibuchi H, Tanaka H and Okada H 1993 An architecture of neural networks with interval weights and its application to fuzzy regression analysis; Fuzzy Sets Syst. 57(1) 27-39.

Lee K H 2009 First Course on Fuzzy Theory and Applications; Springer Berlin-Heidelberg, New York, 340p.

Lin C C, Hong L L, Ueng J M, Wu K C and Wang C E 2005 Parametric identification of asymmetric buildings from earthquake response records; Smart Mater. Struct. 14(4) 850-861.

Lu J, Xue S, Zhang X and Han Y 2015 A neural network based interval pattern matcher; Information 6(3) 388-398.

Masri S F, Smyth A W, Chassiakos A G, Caughey T K and Hunter N F 2000 Application of neural networks for detection of changes in nonlinear systems; J. Eng. Mech. 126(7) 666-676.

Mathur V K, Chakraverty S and Gupta P 2004 Response prediction of typical rural house subject to earthquake motions using artificial neural network; J. Indian Building Congress 11(2) 99-105.

Niksarlioglu S and Kulahci F 2013 An artificial neural network model for earthquake prediction and relations between environmental parameters and earthquakes; Int. J. Environ. 7(2) 65-68.

Okada H, Matsuse T, Wada T and Yamashita A 2012 Interval GA for evolving neural networks with interval weights and biases; SICE Annual Conference, 20-23 August, Akita, Japan, pp. 1542-1545.

Pandey P C and Barai S V 1995 Multilayer perceptron in damage detection of bridge structures; Comput. Struct. 54(4) 597-608.
Reyes J, Esteban A M and Alvarez F M 2012 Neural networks to predict earthquakes in Chile; Appl. Soft Comput. 13(2) 1314-1328.

Sahoo D M, Das A and Chakraverty S 2014 Interval databased system identification of multistorey shear buildings by artificial neural network modelling; Architect. Sci. Rev. 58(3) 244-254.

Sodhi S S and Chandra P 2013 Interval based weight initialization method for sigmoidal feedforward artificial neural networks; 2nd AASRI Conference on Computational Intelligence and Bioinformatics, AASRI Procedia 6 19-25.

Sriram A, Shahryar R and Bourennani F 2014 Artificial neural networks for earthquake anomaly detection; JACIII 18(5) 701-713.

Wang X J and Cui J 2008 A two-step method for structural parameter identification with unknown ground motion; The 14th World Conference on Earthquake Engineering, 12-17 October, Beijing, China, pp. 1-8.

Wang X, Yang H and Qiu Z 2010 Interval analysis method for damage identification of structures; $A I A A$ J. 48(6) 1108-1116.

Wu X, Ghaboussi J and Garett J H 1992 Use of neural networks in detection of structural damage; Comput. Struct. 42(4) 649-659.

Xie J, Qiu J F, Li W and Wang J W 2011 The application of neural network model in earthquake prediction in east China; Chapter in Advances in Computer Science, Intelligent System and Environment 106 79-84.

Xu C, Chase J G and Rodgers G W 2014 Physical parameter identification of nonlinear base-isolated buildings using seismic response data; Comput. Struct. 145 47-57.

Zhang M Q, Beer M and Koh C G 2012 Interval analysis for system identification of linear MDOF structures in the presence of modelling errors; J. Eng. Mech. 138(11) $1326-1338$.

Zhao J, Ivan J N and DeWolf J T 1998 Structural damage detection using artificial neural networks; J. Infrastruct. Syst. 4(3) 93-101.

MS received 30 April 2016; revised 9 August 2016; accepted 17 December 2016

Corresponding editor: N PURNACHANDRA RAO 